\title{
INDICADORES DE TURBULÊNCIA A PARTIR DE PREVISÕES DO MODELO REGIONAL ETA
}

\section{ANDRÉ DE ARRUDA LYRA ${ }^{1}$, CHOU SIN CHAN $^{2}$ e CLAUDINE PEREIRA DERECZYNSKI ${ }^{3}$}

${ }^{1,2}$ Instituto Nacional de Pesquisas Espaciais (INPE), Centro de Previsão do Tempo e Estudos Climáticos. Rod. Presidente Dutra, km 40, SP-RJ, Cachoeira Paulista, SP, Brasil, CEP 12630-000

Tel.: (12) 3186-8400; Fax: (12) 3186-9459

E-mails: ${ }^{1}$ lyra@cptec.inpe.br; ${ }^{2}$ chou@cptec.inpe.br

${ }^{3}$ Universidade Federal do Rio de Janeiro, Centro de Ciências Matemáticas e da Natureza, Instituto de Geociências, Departamento de Meteorologia.

Av. Brigadeiro Trompowski, s/n, Ilha do Fundão, Rio de Janeiro, RJ, Brasil, CEP 21941-890

Tel.: (21) 2598-9532; Fax: (21) 2598-9471

E-mail: claudine@acd.ufrj.br

Recebido Novembro 2004 - Aceito Novembro 2006

\begin{abstract}
RESUMO
A turbulência em ar claro (Clear Air Turbulence - CAT), que ocorre freqüentemente próximo à região de corrente de jato, geralmente em altitudes entre 10.000 e $12.000 \mathrm{~m}$, pode provocar sérios riscos para a aviação. Desta forma, previsões acuradas desse fenômeno contribuem na prevenção de acidentes aéreos e desconforto durante o vôo. Indicadores capazes de detectar esse fenômeno, como turbulência Brown $\left(\Phi_{\mathrm{m}}\right)$, Ellrod (ETI) e o de número de Richardson (Ri) foram calculados a partir das saídas do modelo regional ETA. As previsões de tais indicadores são avaliadas para 2 eventos de 24 de junho de 2003 e de 17 de agosto de 2006, e confrontadas com as informações contidas nas cartas de tempo significativo SIGWX. Os resultados mostram que os três indicadores de turbulência apresentaram boa correlação com as cartas SIGWX. O estudo mostrou a utilidade das previsões do modelo ETA para ajudar a entender o mecanismo da turbulência e para indicar a ocorrência do fenômeno com maior antecedência, por exemplo: $48 \mathrm{~h}$ ou $72 \mathrm{~h}$ comparado às $24 \mathrm{~h}$ de antecedência das cartas SIGWX.

Palavras-chave: turbulência em ar claro, CAT, meteorologia aeronáutica.
\end{abstract}

\begin{abstract}
TURBULENCE INDEX FROM ETA MODEL PREDICTIONS
The Clear Air Turbulence (CAT) which is frequently observed near jet stream regions, usually in the layer between 10,000 and $12,000 \mathrm{~m}$, may cause serious damages to aviation, reaching airplanes without warning. Therefore, predictions of this phenomenon can help to prevent physical damages and discomfort for the crew and passengers. Numerical weather prediction models have been used as powerful tools for operational forecasts of this phenomenon, by application of some indices in the determination of the turbulence areas. In this work, the Brown, Ellrod and Richardson number indices, calculated from ETA model outputs, are used to detect turbulence. The verification was accomplished for 2 events on 24 June 2003 and 17 August 2006 and was based on SIGWX charts. The results show that the three indices correlated well with SIGWX charts. This study showed that the use of ETA model forecasts could help to understand the mechanism of turbulence and to increase the forecast lead time to about $48 \mathrm{~h}$ or $72 \mathrm{~h}$, as compared to 24 -h forecast SIGWX maps.
\end{abstract}

Keywords: Clear Air Turbulence, aviation meteorology, ETA model. 


\section{INTRODUÇÃO}

A turbulência durante vôos pode causar desconforto para a tripulação e passageiros, ou causar danos físicos quando sua intensidade é superior a moderada. Segundo uma pesquisa feita pelo Departamento de Transporte dos Estados Unidos em 1998, a turbulência em vôo foi a principal causa responsável por acidentes sem fatalidades para os passageiros e tripulação (Kaplan et al., 2000). A principal linha aérea dos Estados Unidos relatou, no período de 1981 a 1996, 252 incidentes provocados por turbulência, resultando em duas mortes, 63 passageiros seriamente feridos e 863 passageiros com ferimentos leves. Desta forma, previsões acuradas da ocorrência de turbulência podem contribuir para a prevenção de acidentes com aeronaves.

As características físicas e dinâmicas da atmosfera nas regiões sujeitas à turbulência devem ser bem definidas para previsão do distúrbio. Contudo, a turbulência é um fenômeno de escala sub-sinótica ou de micro-escala, enquanto que a rede de observação de ar superior, principalmente no hemisfério sul, é deficiente, com poucas estações que em geral realizam apenas uma sondagem por dia. Observações feitas por aeronaves poderiam minimizar o problema da falta de dados, particularmente se mantivessem boa freqüência no tempo e no espaço.

Desta forma, os modelos que geram Previsão Numérica de Tempo (PNT) têm sido de grande utilidade para a previsão operacional, utilizando-se de diversos índices na determinação das áreas de turbulência. Previsões de áreas de turbulência são feitas operacionalmente para a América do Norte pelo National Oceanic and Atmospheric Administration (NOAA) usando o modelo Global Forecasting System (GFS) do National Centers for Environmental Prediction (NCEP).

Este trabalho tem por objetivo aplicar os indicadores de turbulência Brown $\left(\Phi_{\mathrm{m}}\right)$, Ellrod (ETI) e o de número de Richardson (Ri) a partir das previsões do modelo regional ETA para detectar as regiões de turbulência sobre a América do Sul.

\section{INDICADORES DE TURBULÊNCIA}

A turbulência se refere ao efeito daqueles movimentos verticais em escalas menores do que o movimento do escoamento básico principal. A turbulência que afeta as operações de vôo é encontrada em muitas situações diferentes de tempo, desde poucos e pequenos solavancos até a turbulência que é suficientemente forte para causar danos à estrutura das aeronaves. A turbulência é classificada de acordo com seu grau de severidade como leve, moderada, severa e extrema (WMO, 1969).

Estudos têm demonstrado que a turbulência pode ocorrer próximo à convecção (Keller et al., 1983; Pantley e Lester, 1990), às montanhas (Lilly, 1971) e aos jatos em altos níveis
(Reiter e Nania, 1964). Endlich (1964), Reiter e Nania (1964), Mancuso e Endlich (1966), Keller (1990), e Ellrod e Knapp (1992) estudaram possíveis relações entre frontogênese, corrente de jato, cisalhamento do vento e a turbulência em ar claro. Roach e Bysouth (2002) apresentaram evidências preliminares que turbulência severa pode ocorrer associada com formação de ondas atmosféricas e com corrente de jato subtropical que gera campos extensivos de turbulência severa.

A turbulência em ar claro é descrita como solavancos perceptíveis em vôos sobre céu claro (Reiter, 1962). De acordo com o National Committee for Clear Air Turbulence (1966), a turbulência em ar claro é definida como qualquer turbulência na atmosfera livre, que afete as operações aeroespaciais, podendo localizar-se fora ou na adjacência de atividade convectiva visível, e que inclui a turbulência encontrada em nuvens cirrus.

Roach (1970) e Reed e Hardy (1972) mostraram que a confluência de dois diferentes fluxos na região de entrada de uma corrente de jato é favorável à geração de turbulência. A probabilidade de ocorrência relacionada com a corrente de jato é ainda maior quando existem dois núcleos de correntes de jato e esses são confluentes a uma distância inferior a 500 $\mathrm{km}$ (aproximadamente $5^{\circ}$ de latitude). O núcleo da corrente de jato posicionado do lado polar está associado com temperaturas mais frias e está localizado em uma altura mais baixa do que o núcleo da corrente de jato do lado equatorial. O resultado é um aumento na estabilidade estática e forte cisalhamento vertical do vento na zona de confluência (WMO, 1969).

Existem dois fatores nos altos níveis geralmente associados com a ocorrência de turbulência induzida por ondas de montanha: o núcleo das correntes de jato e a altura da tropopausa. A área prevista de CAT (clear air turbulence) é centrada no núcleo da corrente de jato, imediatamente a sotavento da linha da cadeia de montanha. Esta área normalmente se estende em torno de $200 \mathrm{~km}$ para cada lado da corrente de jato, e pode se estender de 80 a $200 \mathrm{~km}$ na direção da corrente de jato logo após a cadeia de montanha. As ondas de montanha têm sua amplitude máxima na camada de forte estabilidade, que normalmente é a tropopausa. Então, a localização vertical da área prevista de turbulência induzida por onda de montanha é determinada pela previsão da altura da tropopausa na zona da área de montanha.

Outro mecanismo encontrado como sendo responsável por CAT é a instabilidade de Kelvin-Helmholtz (KHI). Quando um forte cisalhamento existe entre duas camadas de um fluido com densidade estável, a interface da camada deforma-se em uma onda amplificada que finalmente pode quebrar e gerar a turbulência. A fonte de energia para instabilidade de Kelvin-Helmholtz é a energia mecânica produzida pelo cisalhamento vertical do vento. A presença dessas regiões de forte cisalhamento é freqüentemente marcada por formações de nuvens em forma 
de rolo que são às vezes observadas em imagens de satélites ou radar. Uma forte estabilidade estática pode inibir o início da KHI, a menos que o cisalhamento do vento seja suficientemente forte para predominar.

\subsection{Número de Richardson}

Muitos estudos têm sido realizados para gerar métodos objetivos de previsão de CAT (Brown, 1973; Cundy, 1999; Dutton, 1980; Ellrod e Knapp, 1992). Os indicadores de turbulência são baseados em parâmetros meteorológicos como, por exemplo, a estabilidade estática e os cisalhamentos horizontal e vertical do vento. Dependendo da definição de cada indicador, valores acima ou abaixo de limiares específicos são indicativos de potencial de ocorrência de CAT.

O número adimensional de Richardson (Ri) também é usado como parâmetro na medida de possíveis condições de turbulência (Colson, 1963; Rustenbeck, 1963). Sua expressão é derivada de processos dinâmicos que muda os parâmetros da estrutura vertical da atmosfera para produção de turbulência e CAT. Esses parâmetros são a estabilidade estática e o cisalhamento vertical do vetor horizontal do vento, cuja razão define o número de Richardson.

$$
\mathrm{Ri}=\frac{\mathrm{g}}{\theta_{\mathrm{m}}} \times \frac{\frac{\partial \theta}{\partial \mathrm{z}}}{\left(\frac{\left(\Delta \mathrm{u}^{2}+\Delta \mathrm{v}^{2}\right)^{1 / 2}}{\Delta \mathrm{z}}\right)^{2}}
$$

em que g é a aceleração da gravidade $\left(9,8 \mathrm{~m} \cdot \mathrm{s}^{-2}\right)$, u e v são, respectivamente as componentes zonal e meridional do vento, $\Delta z$ é a variação de altura entre dois níveis, $\theta$ é a temperatura potencial e $\theta_{\mathrm{m}}$ representa a temperatura potencial no nível médio da camada. Neste caso, regiões de pequeno Ri, em geral menor que $1 / 4$, devem indicar regiões de turbulência (Dutton e Panofsky, 1970).

Embora Ri fosse julgado ligeiramente melhor que o cisalhamento vertical do vento na identificação de CAT, Kronebach (1964) analisando casos mostrou que áreas onde Ri foi menor do que 1, continham aproximadamente $40 \%$ de todos os casos de CAT. Endlich (1964) sugeriu a partir de seu estudo observacional que condições severas em mesoescala incluindo grandes variações verticais de velocidade e direção do vento, equivalentes a valores pequenos de $\mathrm{Ri}$, fossem considerados na contribuição do desenvolvimento de turbulência. Endlich (1964) também mostrou que valores pequenos de Ri podem ser encontrados tanto em regiões de turbulência quanto em regiões não turbulentas.

Tentativas têm sido feitas para localizar áreas de CAT utilizando campos de Ri produzidos através de sondagens de ar superior. A correlação entre Ri produzido dessa maneira e relatos de CAT é muito pequena, principalmente por causa da baixa resolução vertical dos dados de sondagens de ar superior. Quando Ri é calculado a partir de dados de melhor resolução vertical, por exemplo, de uma aeronave instrumental especial, existe uma correlação maior, sugerindo que a associação de CAT com KHI é basicamente correta (Axford, 1968; Roach, 1970).

\subsection{Indicador Brown}

Roach (1970) tentou contornar o problema da avaliação de Ri a partir de dados sinóticos, identificando áreas onde Ri foi reduzido devido ao escoamento de grande escala. Para deduzir a equação de tendência de Ri, ele considerou que CAT deveria ser representada pela descontinuidade do vento e temperatura no plano vertical pela deformação por cisalhamento e estiramento. Considerando o escoamento como sendo hidrostático, adiabático, invíscido, ele obteve uma expressão para a taxa de mudança logarítmica de Ri, que pode ser descrita pela equação:

$\Phi=-\frac{\mathrm{D}}{\mathrm{Dt}} \ln \mathrm{Ri}=(2 \mathrm{Ri}-1)\left|\frac{\partial \mathrm{V}}{\partial \mathrm{p}}\right|\left|\nabla_{\theta} \mathrm{p}\right| \cos \beta+$

$\left(\frac{\partial \mathrm{u}}{\partial \mathrm{x}}-\frac{\partial \mathrm{v}}{\partial \mathrm{y}}\right) \cos 2 \alpha-\left(\frac{\partial \mathrm{u}}{\partial \mathrm{y}}-\frac{\partial \mathrm{v}}{\partial \mathrm{x}}\right) \operatorname{sen} 2 \alpha$

em que $V$ é o vetor horizontal do vento, $\nabla_{\theta}$ p é o gradiente horizontal de pressão numa superfície isentrópica, $u$ e $v$ são, respectivamente as componentes zonal e meridional do vento, $\alpha$ é o ângulo entre $\frac{\partial \mathrm{V}}{\partial \mathrm{p}}$ e o norte no sentido horário e $\beta$ é o ângulo entre $\frac{\partial \mathrm{V}}{\partial \mathrm{p}}$ e $\nabla_{\theta} \mathrm{p}$ (que é $90^{\circ}$ num escoamento geostrófico).

Roach (1970) comparou Roach (1970) comparou campos de $\Phi$ calculados de dados sinóticos com observações de turbulência severa feitas por aeronaves e encontrou uma correlação pequena entre eles, as vezes $\Phi$ tornava-se negativo na vizinhança da turbulência. Ele observou que as magnitudes dos multiplicadores $\left(\frac{\partial \mathrm{u}}{\partial \mathrm{x}}-\frac{\partial \mathrm{v}}{\partial \mathrm{y}}\right)$ e $\left(\frac{\partial \mathrm{u}}{\partial \mathrm{y}}-\frac{\partial \mathrm{v}}{\partial \mathrm{x}}\right)$ tendem a ser grandes em áreas de CAT. Entretanto o valor de $\Phi$ era sensível à orientação do vetor cisalhamento vertical do vento que pode mudar rapidamente com a altura, especialmente perto da tropopausa.

Brown (1973) modificou essa aproximação removendo os efeitos da flutuação na orientação do vetor cisalhamento vertical do vento. O indicador de turbulência Brown $\Phi_{\mathrm{m}}$ (Eq. 3) é uma simplificação da equação de tendência de Ri (Eq. 2) originalmente derivada por Roach (1970).

$$
\Phi_{\mathrm{m}}=\sqrt{\underbrace{0,3 \times\left(\frac{\partial \mathrm{v}}{\partial \mathrm{x}}-\frac{\partial \mathrm{u}}{\partial \mathrm{y}}+\mathrm{f}\right)^{2}}_{\mathrm{I}}+\underbrace{\left(\frac{\partial \mathrm{v}}{\partial \mathrm{x}}+\frac{\partial \mathrm{u}}{\partial \mathrm{y}}\right)^{2}}_{\mathrm{II}}+\underbrace{\left(\frac{\partial \mathrm{u}}{\partial \mathrm{x}}-\frac{\partial \mathrm{v}}{\partial \mathrm{y}}\right)^{2}}_{\mathrm{III}}}
$$


em que $u$ e $v$ são, respectivamente as componentes zonal e meridional do vento $\left(\mathrm{m} \cdot \mathrm{s}^{-1}\right)$ e $f$ é o parâmetro de Coriolis.

Os termos entre parênteses são: (I) vorticidade absoluta, (II) deformação por cisalhamento e (III) deformação por estiramento. Ao contrário do número de Richardson, quanto maior o indicador de turbulência Brown, maior a probabilidade de ocorrência de CAT.

\subsection{Indicador Ellrod}

O indicador de turbulência Ellrod (ETI) tem sido freqüentemente usado pelo Aviation Weather Center (AWC) para detectar turbulência. Esse indicador é calculado com base no produto do cisalhamento vertical do vento ( $V W S$ ) pela soma da deformação horizontal $(D E F)$ e convergência horizontal ( $C V G)$.

$$
\begin{aligned}
& \mathrm{ETI}=\mathrm{VWS} \times(\mathrm{DEF}+\mathrm{CVG}) \\
& \mathrm{VWS}=\frac{\left(\Delta \mathrm{u}^{2}+\Delta \mathrm{v}^{2}\right)^{1 / 2}}{\Delta \mathrm{z}} \\
& \mathrm{CVG}=-\left(\frac{\partial \mathrm{u}}{\partial \mathrm{x}}+\frac{\partial \mathrm{v}}{\partial \mathrm{y}}\right) \\
& \mathrm{DEF}=\left(\left(\frac{\partial \mathrm{v}}{\partial \mathrm{x}}+\frac{\partial \mathrm{u}}{\partial \mathrm{y}}\right)^{2}+\left(\frac{\partial \mathrm{u}}{\partial \mathrm{x}}-\frac{\partial \mathrm{v}}{\partial \mathrm{y}}\right)^{2}\right)^{1 / 2}
\end{aligned}
$$

em que $u$ e $v$ são, respectivamente as componentes zonal e meridional do vento $\left(\mathrm{m} \cdot \mathrm{s}^{-1}\right)$ e $z$ a altura $(\mathrm{m})$.

Esse indicador Ellrod é derivado da equação da intensidade frontogenética de Pettersen que relaciona frontogênese com aumento do cisalhamento vertical e conseqüentemente probabilidade de turbulência.

\section{METODOLOGIA E DADOS}

Utilizou-se as saídas do modelo regional ETA para o cálculo dos indicadores de turbulência $\Phi_{\mathrm{m}}$, ETI e Ri. As localizações das regiões turbulentas geradas a partir de tais indicadores foram confrontadas com as previsões extraídas das cartas SIGWX. Imagens de satélite e mapas de totais pluviométricos diários foram também utilizados para apoiar a visão geral do quadro sinótico do caso em estudo. As mensagens AIREP e AMDAR foram consultadas para localização das áreas turbulentas, porém pouquíssima informação foi encontrada para o período estudado, na região da América do Sul.

As análises do NCEP e as previsões do modelo ETA para os dias 24 de junho de 2003 e de 17 de agosto de 2006 às 00 UTC elaboradas com 24, 48 e 72 horas de antecedência, obtidas no Centro de Previsão do Tempo e Estudos Climáticos (CPTEC), foram usadas para calcular os indicadores de turbulência $\Phi_{\mathrm{m}}$, ETI e Ri, como descrito a seguir. Além disso, foram confeccio- nadas cartas de pressão ao nível médio do mar, ventos e cartas de linhas de corrente e intensidade do vento ao nível de $250 \mathrm{hPa}$, a partir da análise deste modelo para o período em estudo.

A versão do modelo ETA utilizada neste trabalho foi implementada no CPTEC em janeiro de 2000, e possui a resolução horizontal de $40 \mathrm{~km}$ e vertical de 38 níveis. As condições iniciais no modelo são provenientes do NCEP. As condições de contorno lateral são provenientes das previsões do modelo global do CPTEC e atualizadas a cada seis horas. O domínio do modelo cobre a maior parte da América do Sul e parte dos oceanos adjacentes, desde $50,2^{\circ} \mathrm{S}$ a $12,2^{\circ} \mathrm{N}$ e $83^{\circ} \mathrm{W}$ a $25,2^{\circ} \mathrm{W}$.

As cartas SIGWX para o nível FL250/FL630, ou seja, 25.000 pés $(7.500 \mathrm{~m}) / 63.000$ pés $(18.900 \mathrm{~m})$, do período de 22 a 25 de junho de 2003 e para o dia 17 de agosto de 2006 às 00 UTC foram utilizadas para confrontar regiões previstas de ocorrência de turbulência com os resultados obtidos a partir dos indicadores calculados neste trabalho. Essas cartas foram obtidas da Rede de Meteorologia do Comando da Aeronáutica (no endereço: http://www.redemet.aer.mil.br). Os dados de precipitação acumulada diária foram obtidos na página do CPTEC/INPE, no endereço: http://www.cptec.inpe.br/clima/ monit/monitor_as.shtml.

\section{RESULTADOS}

Neste item os indicadores de turbulência $\Phi_{\mathrm{m}}$, ETI e Ri são avaliados para os eventos ocorridos em 24 de junho de 2003 e 17 de agosto de 2006. As análises e previsões do modelo ETA são comparadas com as cartas SIGWX. A fim de apoiar a interpretação dessas análises é feita inicialmente uma breve descrição das condições sinóticas para o primeiro caso em estudo.

\subsection{Análise Sinótica}

A Figura 1 apresenta o campo de linha de corrente e intensidade do vento ao nível de $250 \mathrm{hPa}$. Destaca-se a presença de uma corrente de jato subtropical com núcleo superior a $60 \mathrm{~ms}^{-1}$, situado em aproximadamente $40^{\circ} \mathrm{S}, 75^{\circ} \mathrm{W}$ no dia 22 de junho de 2003. O jato subtropical se desloca para leste nos dias seguintes, com expansão da área do núcleo de velocidade máxima. Pode-se observar também um cavado localizado a leste do jato sobre o oceano Atlântico nos dias 22 e 23. O jato apresenta curvatura anticiclônica.

Em baixos níveis, as cartas de pressão ao nível médio do mar (NMM) e ventos (Figura 2) mostram um sistema frontal (SF) com rápido deslocamento pelo Oceano Atlântico, atingindo o Rio Grande do Sul no dia 22 de junho de 2003 às 0000 UTC e chegando 12 horas depois no litoral entre o Rio de Janeiro e o Espírito Santo. Um ciclone com pressão central inferior a $996 \mathrm{hPa}$, associado a este SF se localiza no oceano, em aproxi- 

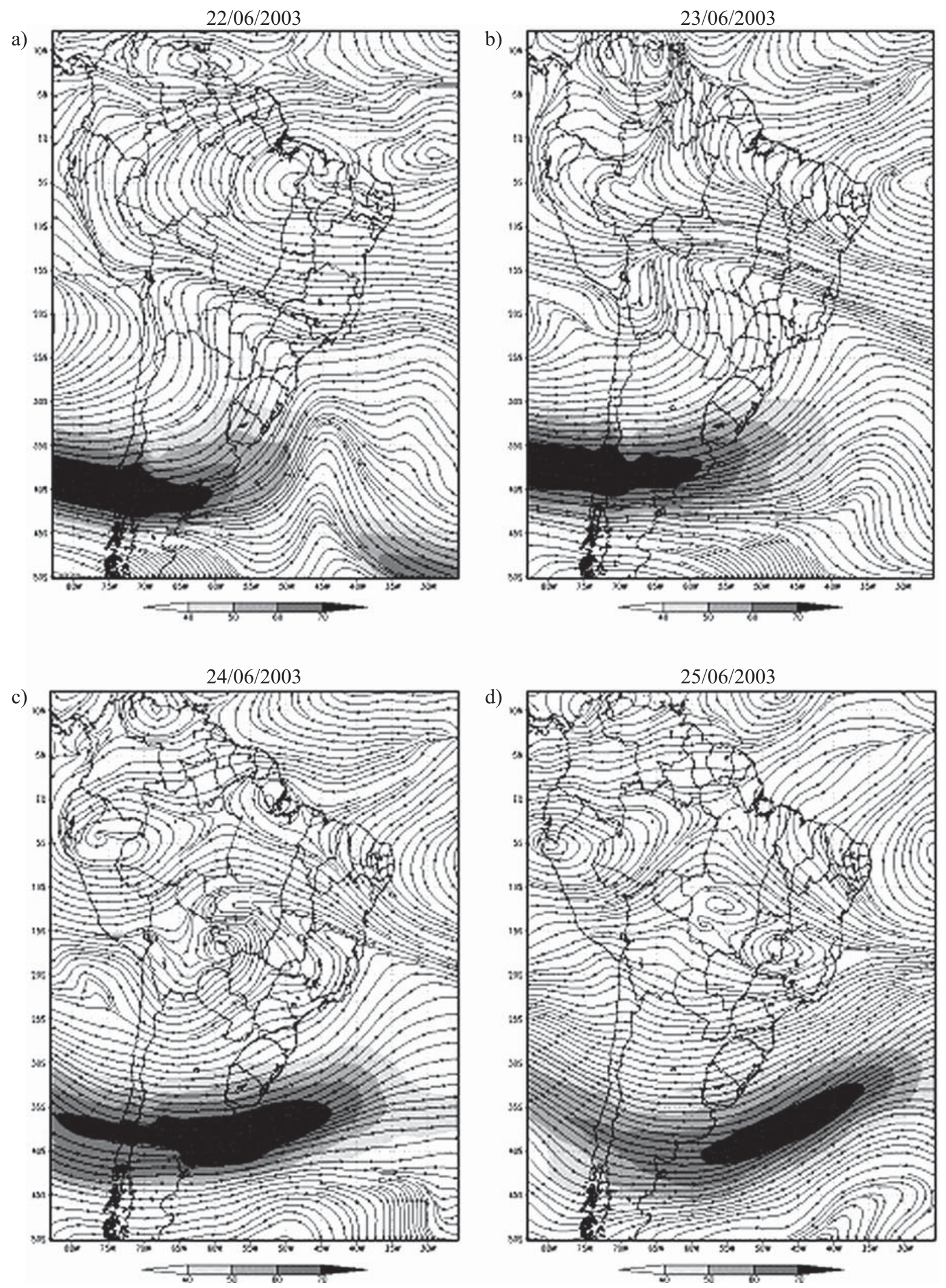

Figura 1 - Linhas de corrente e intensidade do vento (m/s) ao nível de $250 \mathrm{hPa}$ para os dias (a) 22, (b) 23 , (c) 24 e (d) 25 de junho de 2003 às 0000 UTC. 
madamente $40^{\circ} \mathrm{S} / 35^{\circ} \mathrm{W}$, no dia 22 às $1200 \mathrm{UTC}$ (Figura $2 \mathrm{~b}$ ). A partir desta data o ciclone deslocou-se lentamente para sudeste, localizando-se a leste de $25^{\circ} \mathrm{W}$ a partir do dia 24 às 0000 UTC (Figura 2d). No dia 25, o continente passou a ser dominado por um sistema de alta pressão com valores acima de $1.012 \mathrm{hPa}$.

As imagens de satélite apresentadas na Figura 3, mostram o deslocamento do sistema frontal pelo oceano, com pouca nebulosidade sobre o continente. Nos dias 22 e 23, observa-se sobre a Argentina, na altura de Bahia Blanca, a nebulosidade provocada por um jato nos altos níveis. Nota-se que nos dias 24 e 25 a nebulosidade diminui bastante no sul do continente estando presente apenas sobre o oceano e Amazônia. Sobre o oceano, em latitudes próximas a SC (indicado pela seta) nota-se a presença de outra banda de nebulosidade.

Os campos de precipitação para o período em estudo mostram que os maiores totais pluviométricos diários ocorreram no norte da América do Sul. No Sul do país, a frente fria causou chuvas no Rio Grande do Sul apenas no dia 22. No Sudeste e Centro-Oeste praticamente não ocorreu precipitação nesse período. No sul do continente as chuvas estão associadas à uma região de baixa pressão predominante na área durante a maior parte do período estudado.

\subsection{A turbulência}

Nesta seção são apresentados os indicadores de turbulência Brown, Ellrod e Número de Richardson calculados a partir das análises do NCEP e previsões do modelo regional ETA para os eventos de 24 de junho de 2003 e 17 de agosto de 2006. Tais resultados são comparados com as cartas SIGWX de níveis superiores ( 25.000 a 63.000 pés), onde são fornecidas previsões subjetivas com 12 horas de antecedência das condições atmosféricas mais relevantes para aviação, incluindo a turbulência em ar claro.

As cartas SIGWX para o período de 22 a 25 de junho de 2003 são apresentadas na Figura 4. No dia 22 de junho de 2003 às 0000 UTC verificam-se duas áreas de turbulência moderada no nível de 35.000 pés (aproximadamente 10.500 metros) sobre o Oceano Atlântico, uma maior estendendo-se de aproximadamente $30^{\circ} \mathrm{S}$ a $55^{\circ} \mathrm{S}$ e outra de menor extensão entre $40^{\circ} \mathrm{S}$ e $48^{\circ} \mathrm{S}$. No dia 23, não foi previsto turbulência, provavelmente por falha ou falta de dados (Figura 4b). No dia 24, a carta da Figura 4c mostra uma grande área com turbulência moderada até 39.000 pés (aproximadamente 11.000 metros) cruzando a parte central da Argentina de $95^{\circ} \mathrm{W}$ até $36^{\circ} \mathrm{W}$, duas áreas menores de turbulência podem ser observadas no Oceano Atlântico entre $15^{\circ} \mathrm{S}$ e $35^{\circ} \mathrm{S}$. No dia 25 , continuam sendo previstas turbulências sobre a Argentina e sul do Oceano Atlântico (Figura 4d).

A carta SIGWX para o caso do dia 17 de agosto de 2006 é apresentada na Figura 5a. Neste dia, observa-se uma grande área de turbulência a partir de 37.000 pés de altitude que cobre uma faixa entre as latitudes $30^{\circ} \mathrm{S}$ e $40^{\circ} \mathrm{S}$ do Oceano Atlântico atingindo parte do Uruguai e Rio Grande do Sul. A Figura 5c mostra um jato subtropical relacionado com a região de turbulência apresentada na carta SIGWX. A Figura $5 \mathrm{~b}$ mostra a região de nebulosidade associada com o jato subtropical.

\subsubsection{Indicador de Turbulência Brown}

$\mathrm{O}$ indicador de turbulência Brown foi calculado a partir das análises do NCEP na grade do modelo regional ETA. A importância relativa de cada um dos termos I, II e III que compõe $\mathrm{o}$ indicador (Eq. 3) foi analisada. Os termos foram analisados para o período de 22 a 25 de junho de 2003, entretanto apenas a figura referente ao dia 24 será apresentada.

No dia $22 \mathrm{em} 250 \mathrm{hPa}$, o termo I proporcional a vorticidade absoluta e o termo II proporcional ao cisalhamento apresentaram valores máximos de aproximadamente $180 \times 10^{-10} \mathrm{~s}^{-2,} \mathrm{e}$ orientação no sentido norte/sul, estes máximos estão associados ao cavado que se estendia sobre o Oceano Atlântico, desde $30^{\circ} \mathrm{S}$ até $50^{\circ} \mathrm{S}$ e aproximadamente $45^{\circ} \mathrm{W}$. Nota-se um máximo secundário de $120 \times 10^{-10} \mathrm{~s}^{-2}$ ao sul em torno de $45^{\circ} \mathrm{S}$ associado à corrente de jato polar em $250 \mathrm{hPa}$ (Figura 1a). Nota-se que o termo do estiramento, termo III, apresentou uma contribuição menor do que os dois outros termos sobre o oceano, porém maior sobre o continente. $\mathrm{O}$ indicador de turbulência Brown para este dia mostra as duas regiões citadas anteriormente, com valores de turbulência mais intensa associada à região frontal coincidindo com a área principal de turbulência demarcada na carta SIGWX (Figura 4a).

No dia 23, com o deslocamento do sistema frontal para leste, sobre o Oceano Atlântico, a região de "máximo principal" deslocou-se sobre o continente para o norte da Região Sudeste, atingindo também a Região Centro-Oeste. Os três termos se intensificaram sobre o continente, sendo que a participação do termo de estiramento, com valores de $140 \times 10^{-10} \mathrm{~s}^{-2}$, tornouse mais importantes do que a vorticidade absoluta com cerca $80 \times 10^{-10} \mathrm{~s}^{-2}$ e o cisalhamento com cerca $80 \times 10^{-10} \mathrm{~s}^{-2}$. A carta SIGWX para este dia (Figura $4 \mathrm{~b}$ ) não mostra esta região com possibilidade de turbulência, contudo, pode ter havido omissão ou falha humana, uma vez que esta previsão é elaborada subjetivamente. A região de "máximo secundário", citada anteriormente desintensificou-se nos três termos, porém ainda pode ser observada no indicador de turbulência $\Phi_{\mathrm{m}}$. Nota-se também que $\mathrm{o}$ indicador de turbulência Brown mostrou apenas uma região com valores acima de $15 \times 10^{-5} \mathrm{~s}^{-1}$ sobre Goiás e Minas Gerais.

No dia 24 (Figura 6), o $\Phi_{\mathrm{m}}$ reduziu devido a redução na intensidade dos três termos na região frontal, apesar de ainda se observar uma região favorável à turbulência no dia 24 , sobre o sul da Bahia e norte de Minas Gerais no campo do indicador de turbulência Brown (Figura 7a). Entretanto a carta SIGWX 

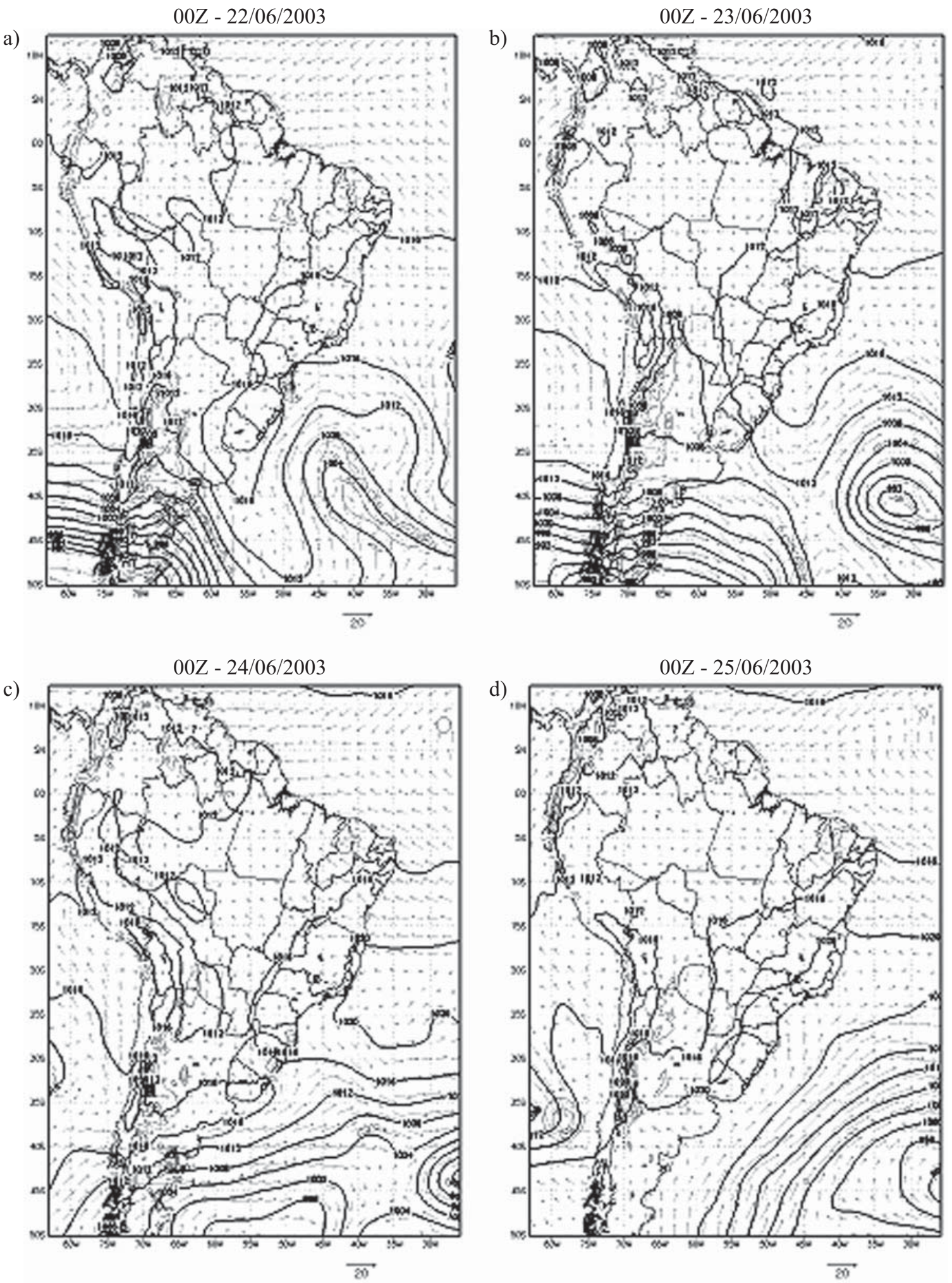

Figura 2 - Pressão ao NMM (linhas pretas, intervalo: $4 \mathrm{hPa}$ ) e ventos (m/s) (setas cinzas) ao nível de $1000 \mathrm{hPa}$, para os dias (a) 22, (b) 23, (c) 24 e (d) 25 de junho de 2003 às 0000 UTC. 
22/06/03 - 00Z

a)

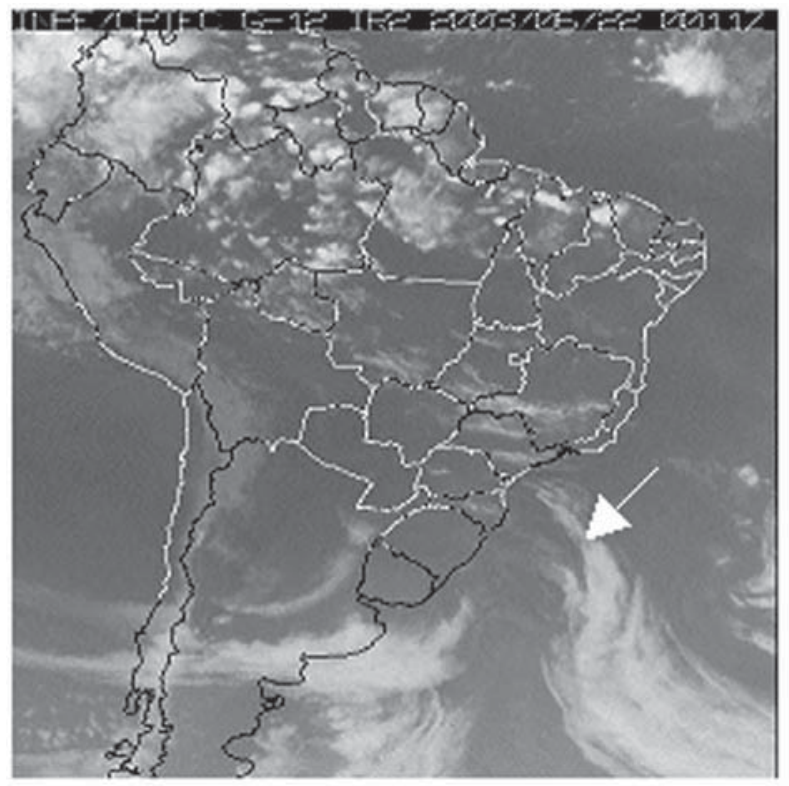

24/06/2003 - 00Z

c)

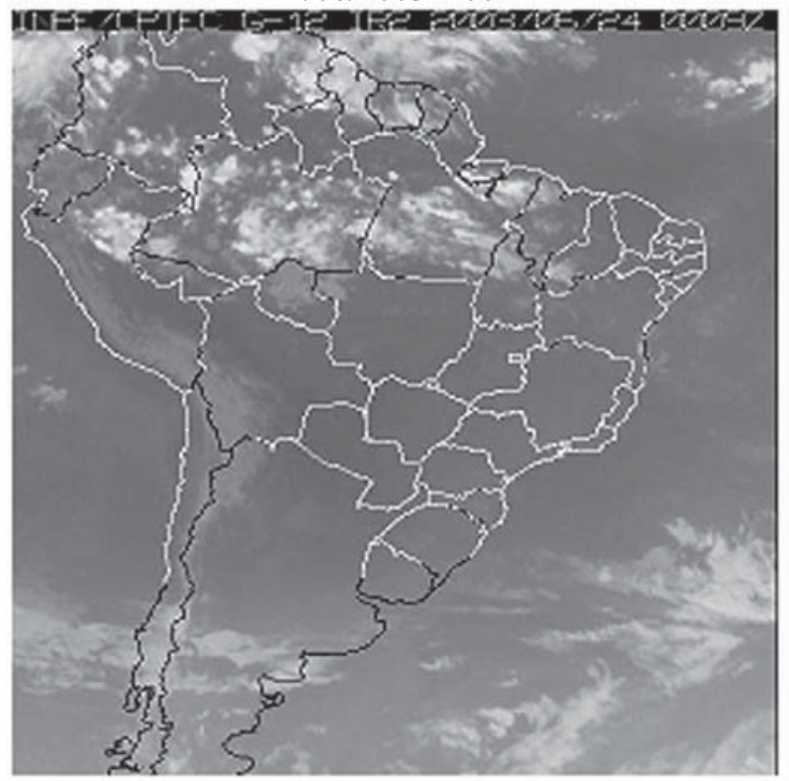

$23 / 06 / 2003-00 Z$

b)

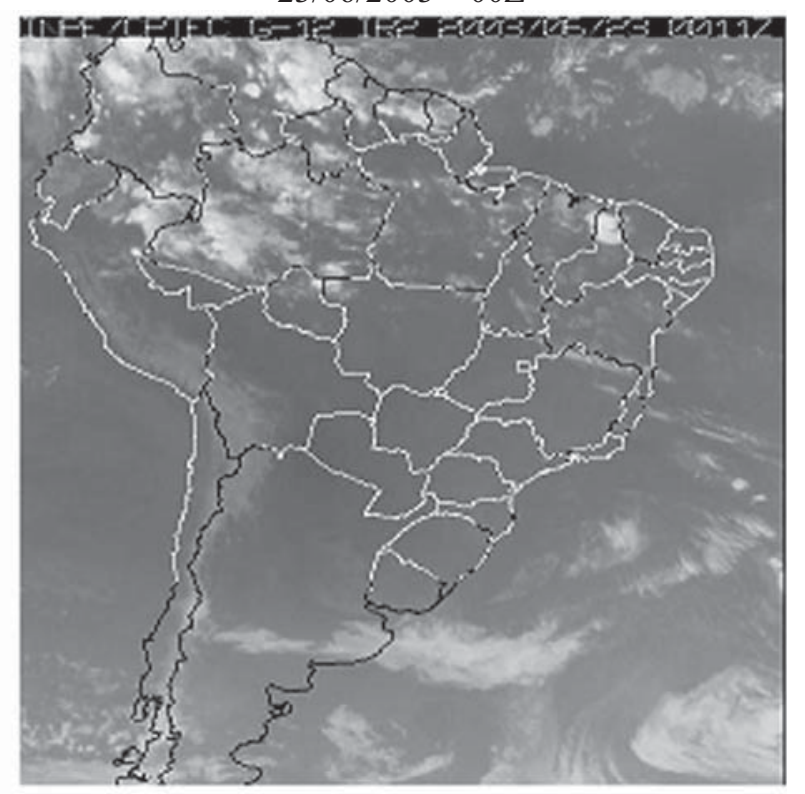

$25 / 06 / 2003-00 Z$

d)

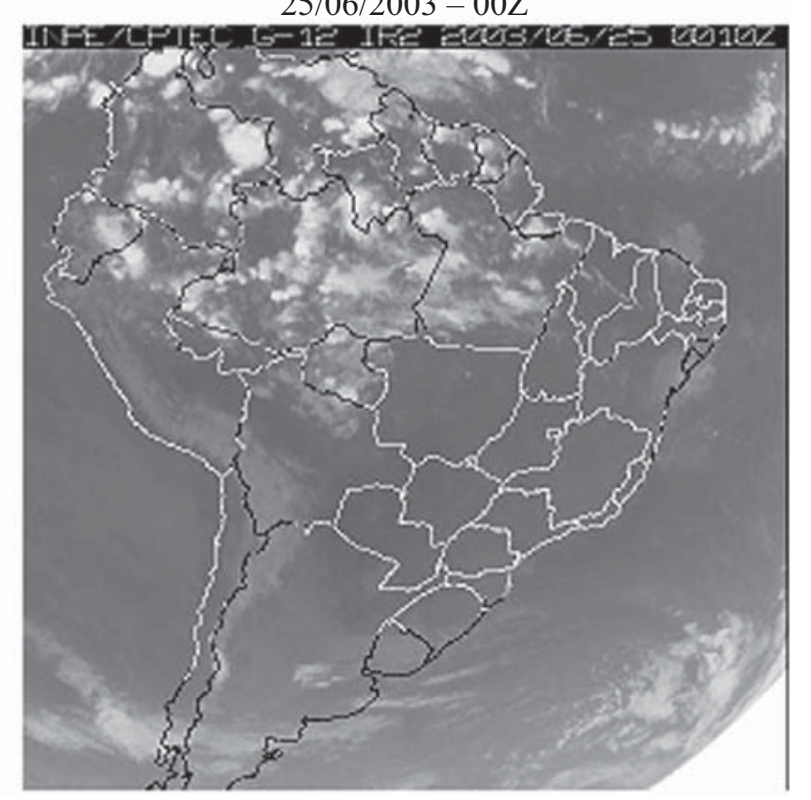

Figura 3 - Imagens do satélite GOES no canal infravermelho Fonte: INPE/CPTEC 
a)

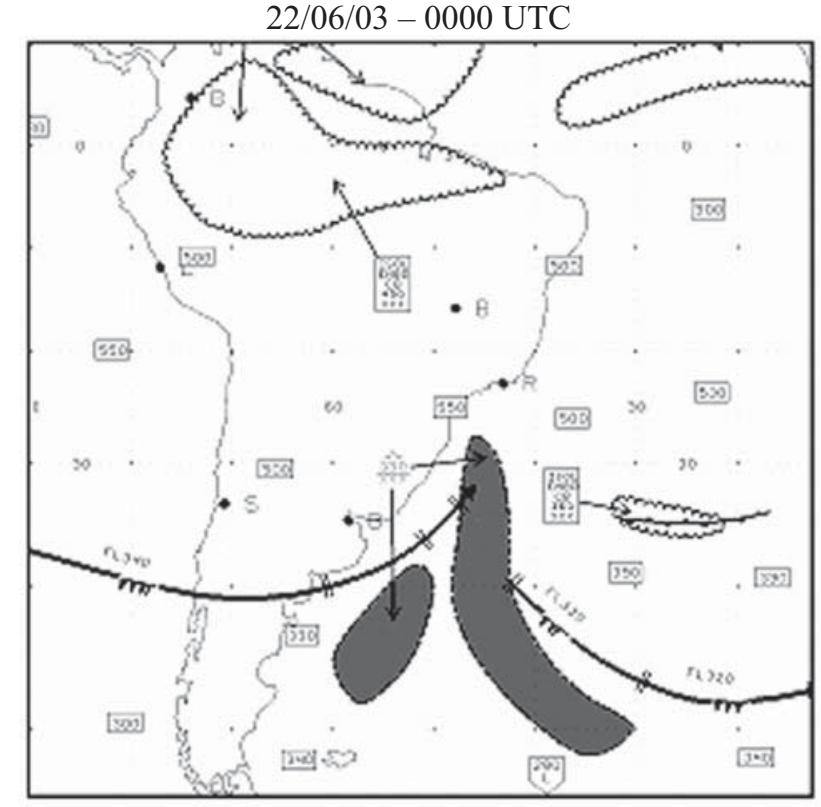

c)

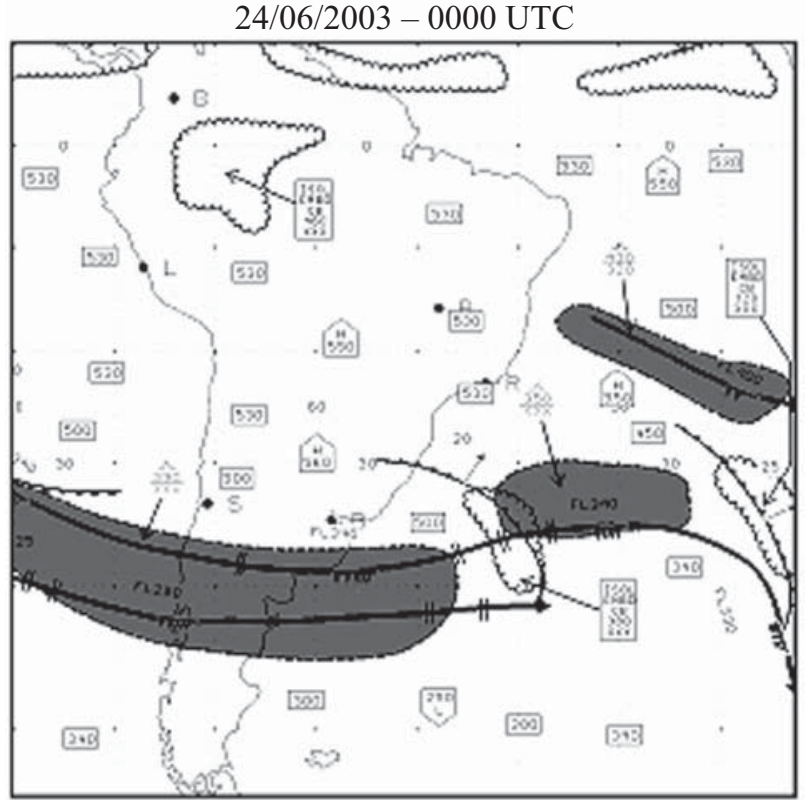

b)

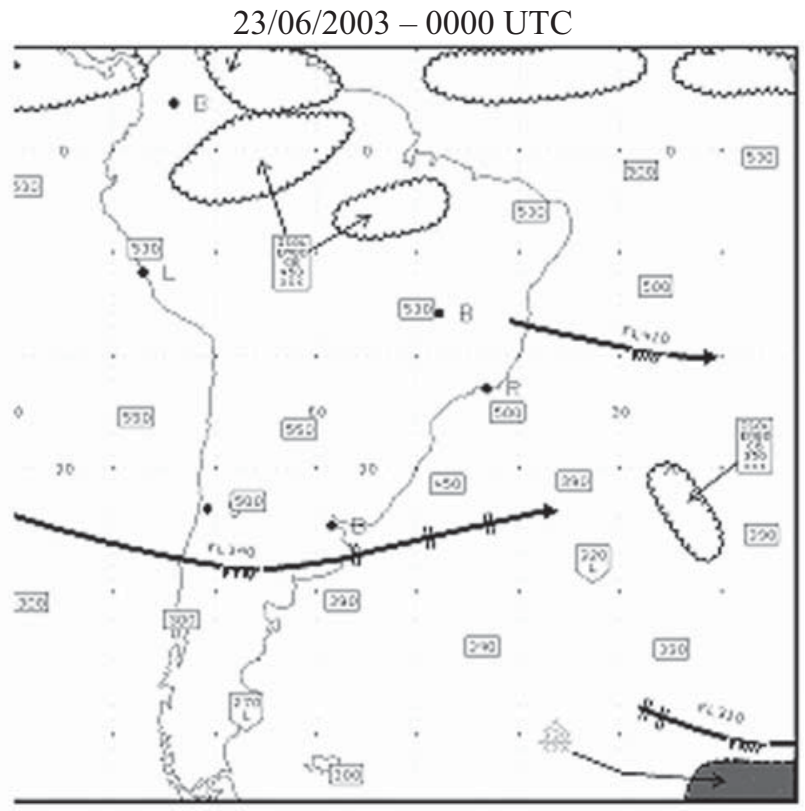

d)

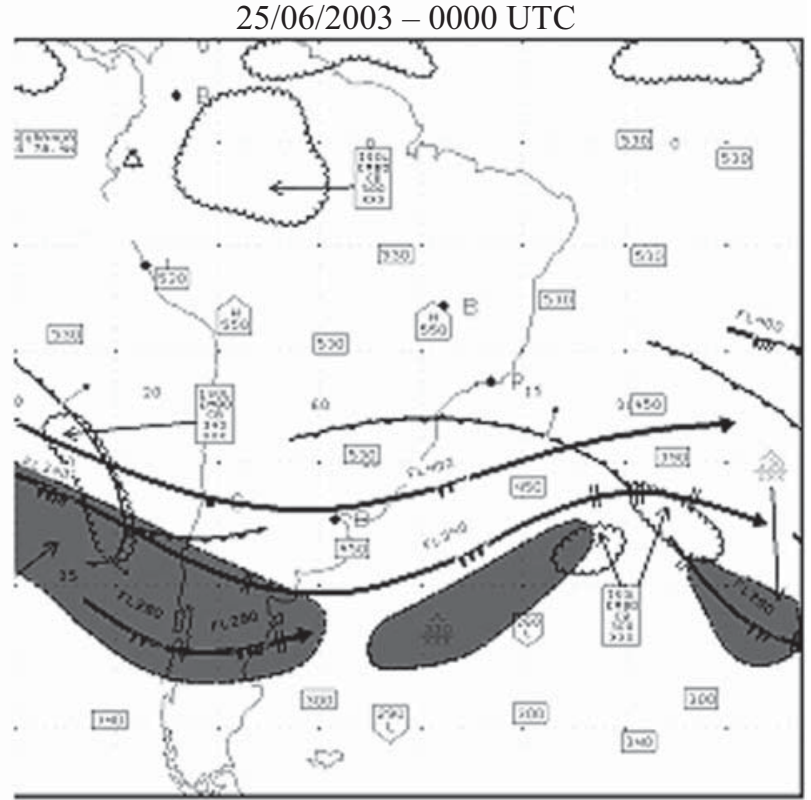

Figura 4 - Cartas SIGWX - FL250/630, para (a) 22, (b) 23, (c) 24 e (d) 25 de junho de 2003 às 0000 UTC. Áreas de turbulência são sombreadas e o símbolo $\_$indica a intensidade. (Fonte: Rede de Meteorologia do Comando da Aeronáutica: www.redemet.aer.mil.br) 
a)

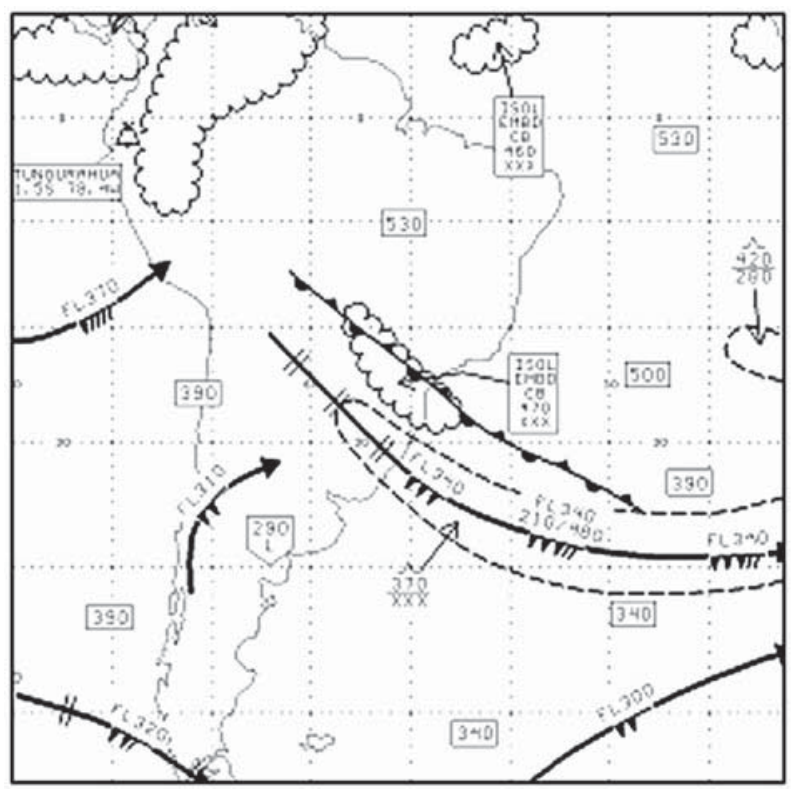

b)

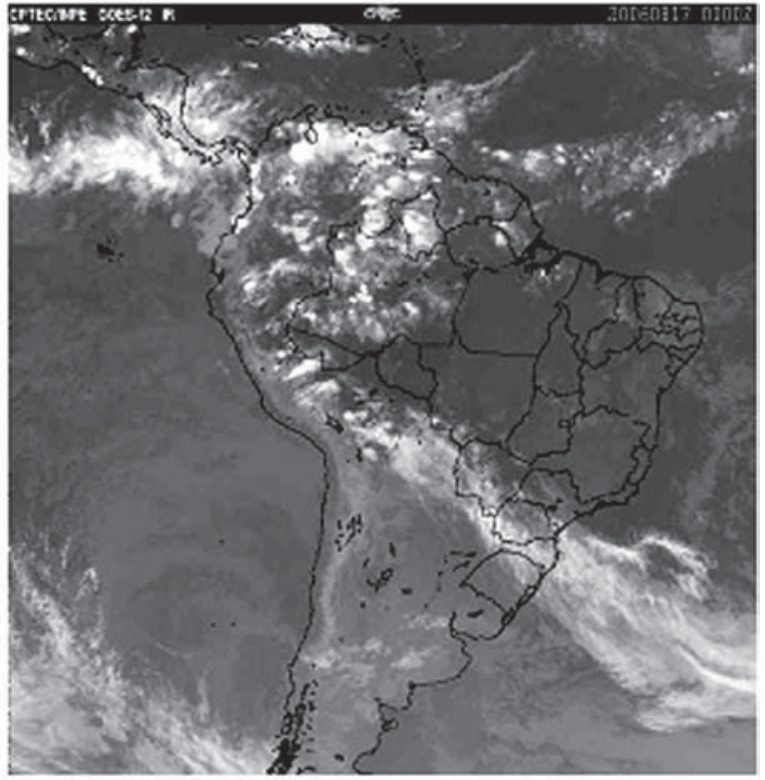

c)

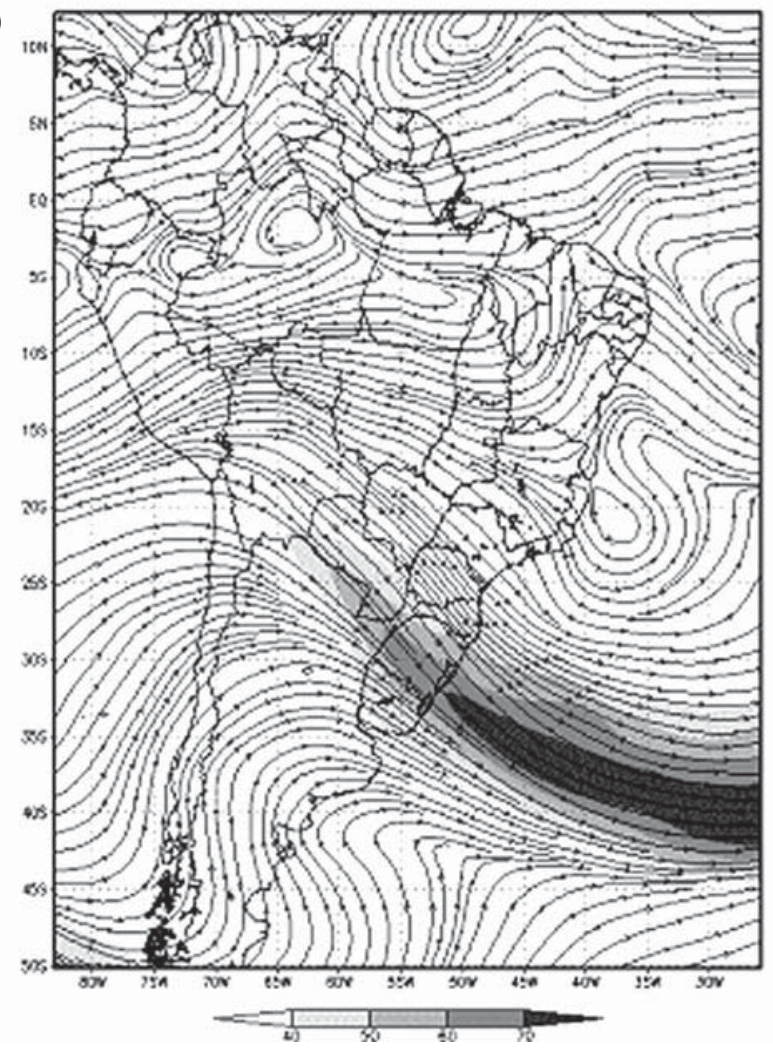

Figura 5 - (a) Cartas SIGWX - FL250/630, (b) Imagens do satélite GOES no canal infravermelho, (c) Linhas de corrente e intensidade do vento $(\mathrm{m} / \mathrm{s})$ ao nível de $250 \mathrm{hPa}$ para 17 de agosto de 2006 às 0000 UTC. 

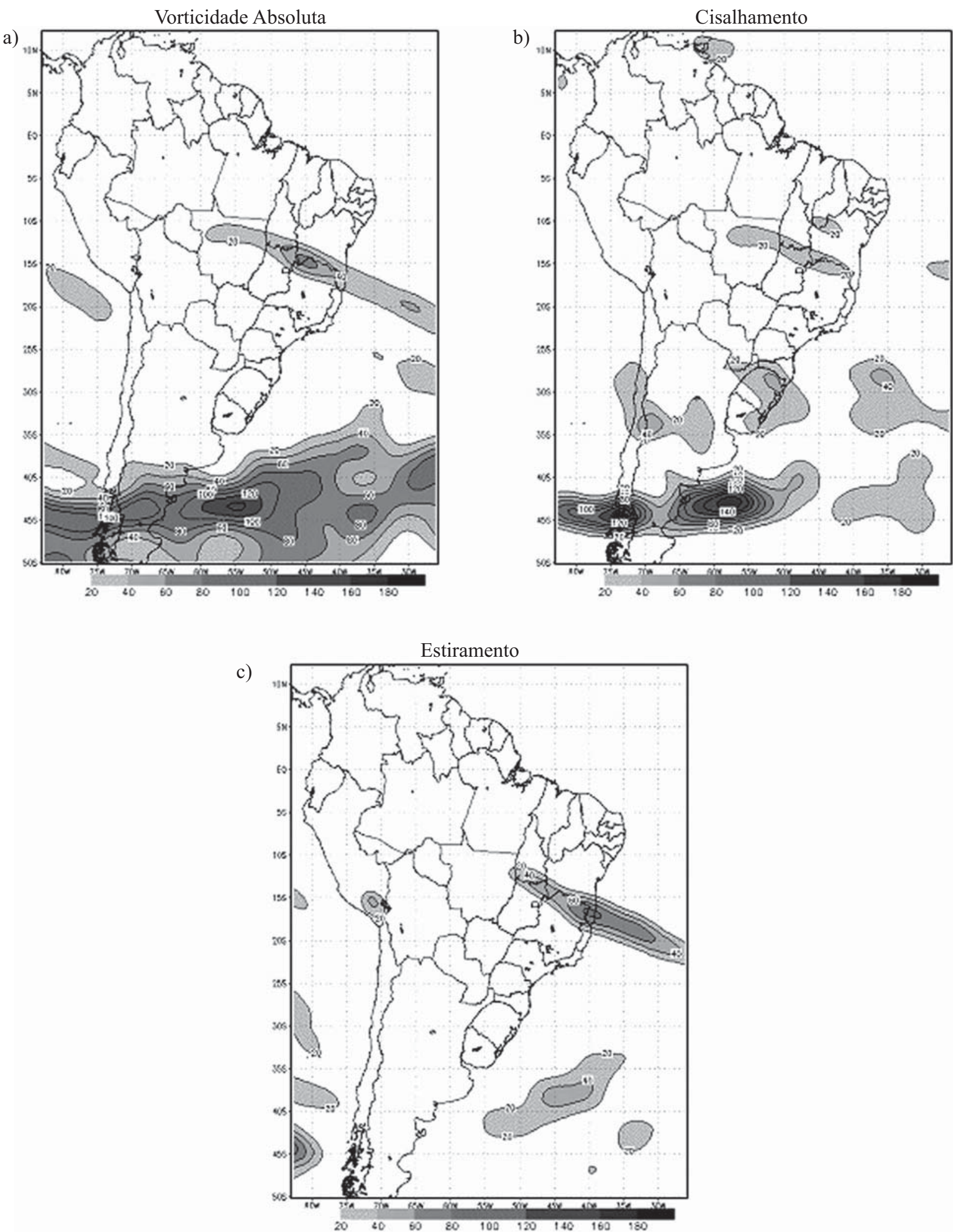

Figura 6 - Análise do NCEP do dia 24 de junho de 2003 às 0000 UTC para os termos (a) da vorticidade absoluta $\left(10^{-10} \mathrm{~s}^{-2}\right)$, (b) do cisalhamento $\left(10^{-10} \mathrm{~s}^{-2}\right)$ e (c) do estiramento $\left(10^{-10} \mathrm{~s}^{-2}\right)$. 
do mesmo dia reporta essa turbulência apenas sobre o Oceano Atlântico na altura do sul da Bahia (Figura 4c). Neste mesmo dia, o termo de cisalhamento teve maior contribuição, com valores superiores a $140 \times 10^{-10} \mathrm{~s}^{-2}$ no sul da Argentina. O indicador de turbulência Brown e a carta SIGWX concordam na mesma região com possibilidade de turbulência. No dia 25 , as regiões de turbulência indicadas por $\Phi_{\mathrm{m}}$ e a carta SIGWX (Figura 4d) apresentaram um pequeno deslocamento para sul.

$\mathrm{O}$ indicador de turbulência Brown foi também calculado a partir das previsões do modelo ETA para os dias 24 de junho de 2003 e 17 de agosto de 2006, elaboradas com 24, 48 e 72 horas de antecedência.

A Figura 7 apresenta a análise e as previsões de 24, 48 e 72 horas para o dia 24 de junho de 2003. O modelo previu a região de turbulência associada com o sistema frontal em todos os prazos de previsão, contudo ela foi representada com maior extensão e intensidade nas previsões de 48 e 72 horas. Esta intensificação decorre do afastamento na integração das condições iniciais de baixa resolução geradas pelo NCEP. A maior resolução do modelo ETA em relação à análise permite circulações mais vigorosas. A região turbulenta associada à corrente de jato foi bem representada em todas as previsões. Com relação à região de turbulência associada à corrente de jato nota-se que o modelo indicou a região corretamente.

No caso do dia 17 de agosto de 2006 (Figura 8), a turbulência estava associada à uma região de um jato em altos níveis. O modelo representou satisfatoriamente a área de turbulência sobre o sul da região sul do Brasil e parte do Oceano Atlântico com até 72 horas de antecedência. Para este caso, os termos II e III apresentaram a maior contribuição com valores máximos próximos a $140 \times 10^{-10} \mathrm{~s}^{-2}$ na região de turbulência mostrada na Figura 5a.

\subsubsection{Indicador de turbulência Ellrod}

$\mathrm{O}$ indicador de turbulência Ellrod foi calculado, bem como a contribuição de cada um dos seus termos (Equações 4, 5 e 6). A Figura 9 apresenta o campo de deformação horizontal (termo I), convergência do vento (termo II), cisalhamento vertical do vento (termo III) e o indicador de turbulência Ellrod para o dia 24 de junho de 2003.

No dia 22 de junho de 2003 os três termos foram bastante pronunciados próximos ao sistema frontal, resultando em áreas favoráveis à ocorrência de turbulência com ETI $>4$. As áreas de divergência do vento apresentaram tendência de redução do indicador de turbulência, principalmente na região próxima à corrente de jato.

No dia 23, o termo de deformação horizontal torna-se mais significativo sobre o continente com valores máximos chegando a $120 \times 10^{-6} \mathrm{~s}^{-1}$, enquanto que nos dias 24 e 25 os maiores valores aparecem na região associada à corrente de jato (Figura 9).
As Figuras 10 e 11 apresentam as análises e as previsões de 24, 48 e 72 horas para os dias 24 de junho de 2003 e 17 de agosto de 2006 respectivamente. A região de turbulência foi bem representada pelo modelo ETA nas regiões associadas ao sistema frontal e a corrente de jato, principalmente nas previsões de 24 e 48 horas no primeiro caso. No segundo caso, a região de turbulência sobre o oceano foi bem representada nas previsões de 24 e 48 horas, entretanto apenas a previsão de 48 horas indicou a região de turbulência sobre a Região Sul.

\subsubsection{Indicador de turbulência de número de Richardson}

$\mathrm{O}$ indicador de turbulência de número de Richardson (Ri) também foi calculado avaliando a contribuição dos seus dois termos: a estabilidade estática e o cisalhamento vertical do vento. A Figura 12 apresenta o termo proporcional a estabilidade estática, o termo proporcional ao cisalhamento vertical do vento e o indicador de turbulência Ri para o dia 24 de junho de 2003. Quanto menor o número de Richardson, maior será a possibilidade de ocorrer turbulência, sendo que valores menores que 0,25 são mais favoráveis à ocorrência. Com relação à contribuição dos termos, quanto menor a estabilidade estática e maior o cisalhamento vertical do vento, menor será o número de Richardson, portanto regiões vizinhas ao núcleo do jato ou regiões com atividade convectiva são propícias à turbulência.

No dia 22, observou-se que a região na vanguarda do sistema frontal e a região próxima ao núcleo corrente de jato são regiões de baixos valores de estabilidade estática e de forte cisalhamento vertical do vento. No dia 23 , apesar do deslocamento do sistema frontal para o Oceano, uma grande região de forte cisalhamento vertical do vento com valores de $18 \times 10^{-3} \mathrm{~s}^{-1}$ pode ser observada sobre o sul do Brasil e Uruguai. No dia 24, ainda se observa uma região de cisalhamento com um pequeno núcleo com valores acima de $18 \times 10^{-3} \mathrm{~s}^{-1}$ associada ao sistema frontal (Figura 12). No dia 25, as regiões de forte cisalhamento vertical do vento e baixos valores de estabilidade estática estão localizadas próximas à corrente de jato.

Nota-se durante todo o período de estudo que o indicador de turbulência Ri é controlado principalmente por valores maiores do cisalhamento (valores acima de $12 \times 10^{-3} \mathrm{~s}^{-1}$ ) e por valores negativos de estabilidade estática. As regiões de turbulência associadas aos valores negativos de estabilidade estática, não correspondem a nenhuma região de turbulência prevista pelas cartas SIGWX. As outras regiões de turbulência apresentadas por esse indicador foram representadas por áreas menores que as reportadas pelas cartas SIGWX.

$\mathrm{O}$ indicador de turbulência Ri também foi calculado a partir das previsões do modelo regional ETA para os dias 24 de junho de 2003 e para o dia 17 de agosto de 2006, elaboradas com 24,48 e 72 horas de antecedência. 
Análise

a)

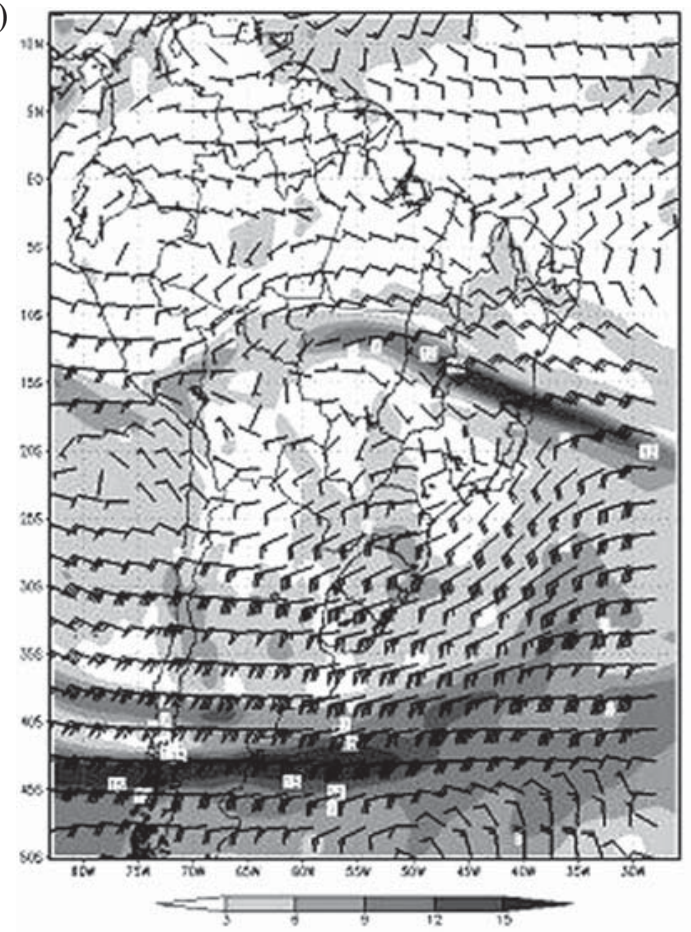

Previsão 48h

c)

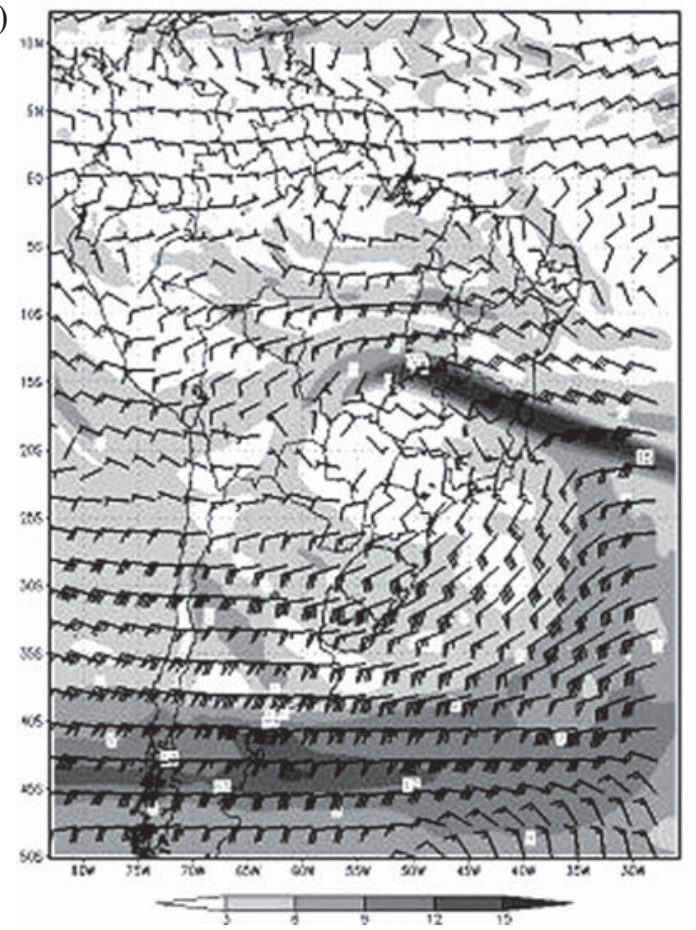

Previsão $24 \mathrm{~h}$

b)

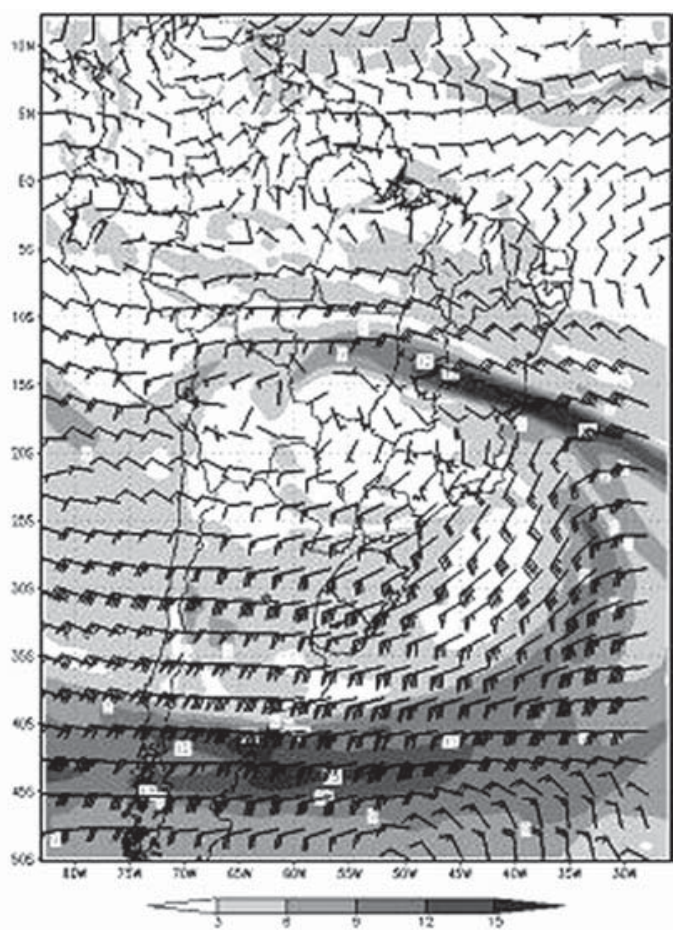

Previsão $72 \mathrm{~h}$

d)

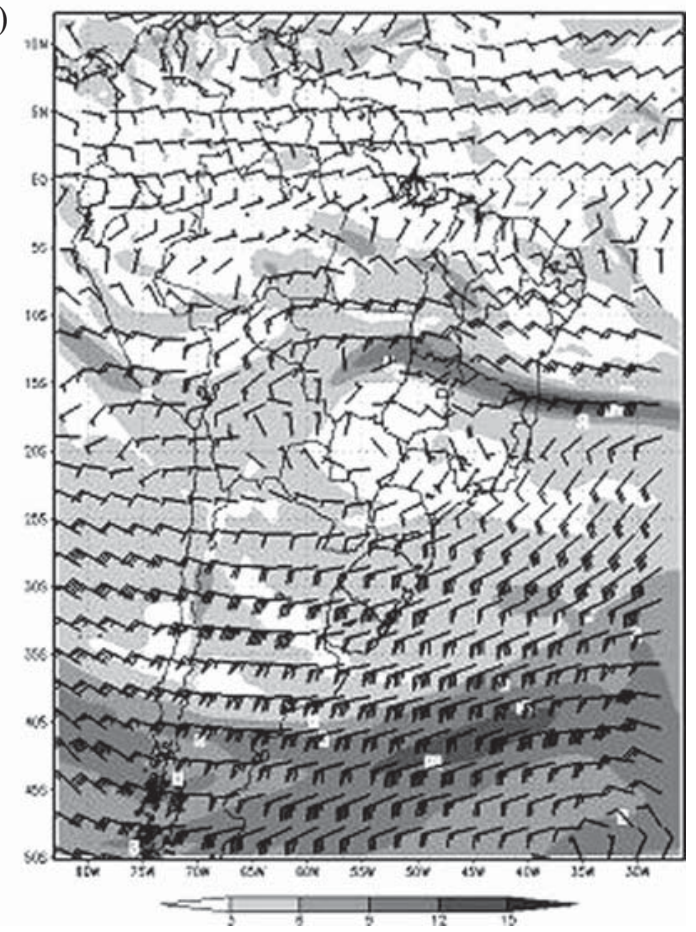

Figura 7 - Indicador de turbulência Brown $\left(10^{-5} \mathrm{~s}^{-1}\right)$ em $250 \mathrm{hPa}$ calculado a partir da saída do modelo ETA para o dia 24 de junho de 2003 às 0000 UTC com (a) 00h (análise), (b) 24h, (c) 48h e (d) 72h de antecedência. 
Análise

a)

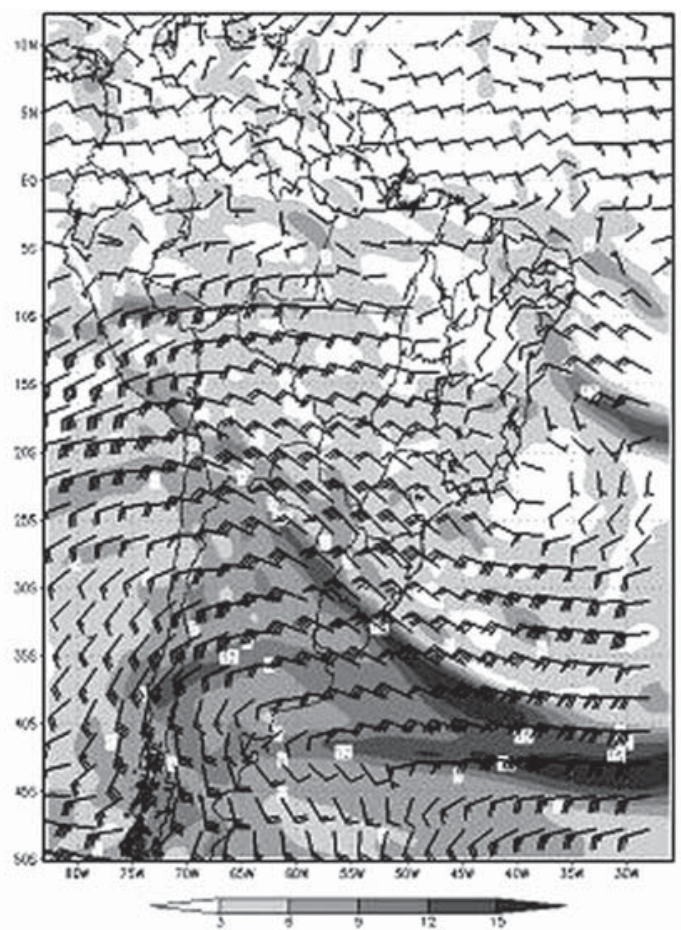

Previsão $48 \mathrm{~h}$

c)

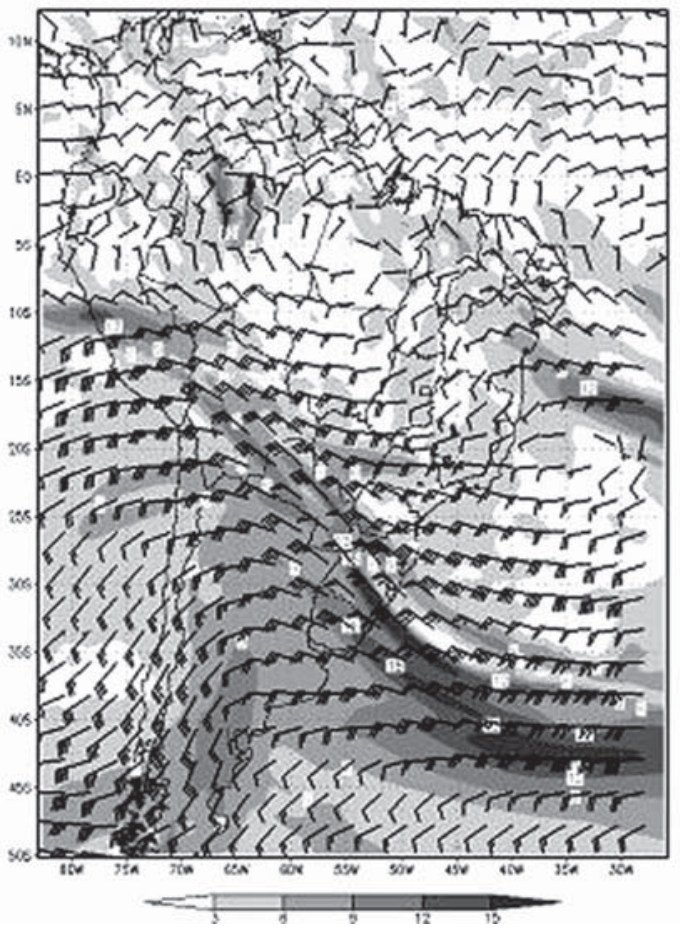

Previsão $24 \mathrm{~h}$

b)

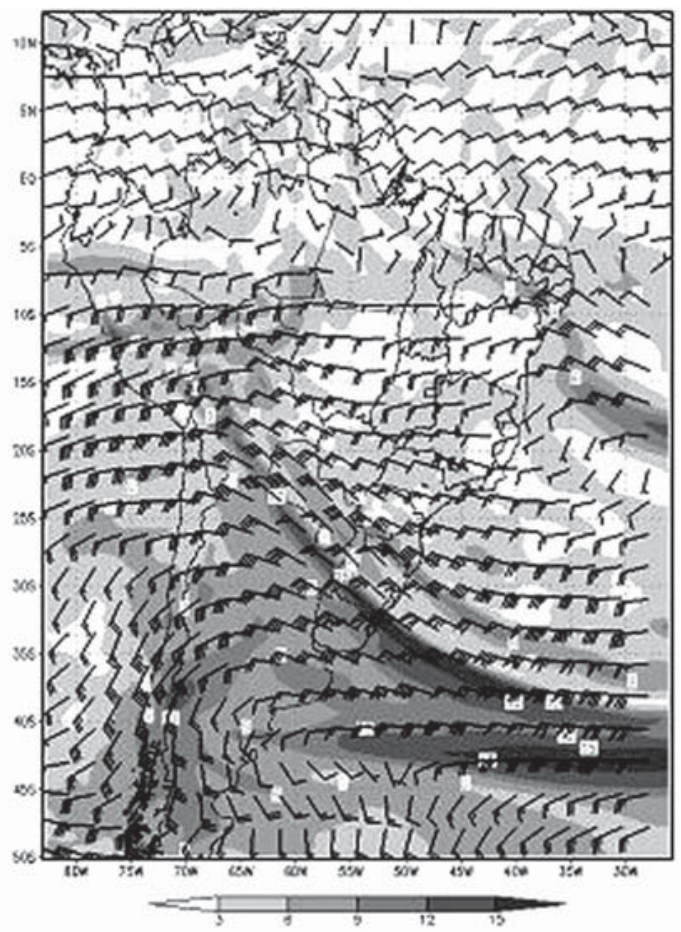

Previsão $72 \mathrm{~h}$

d)

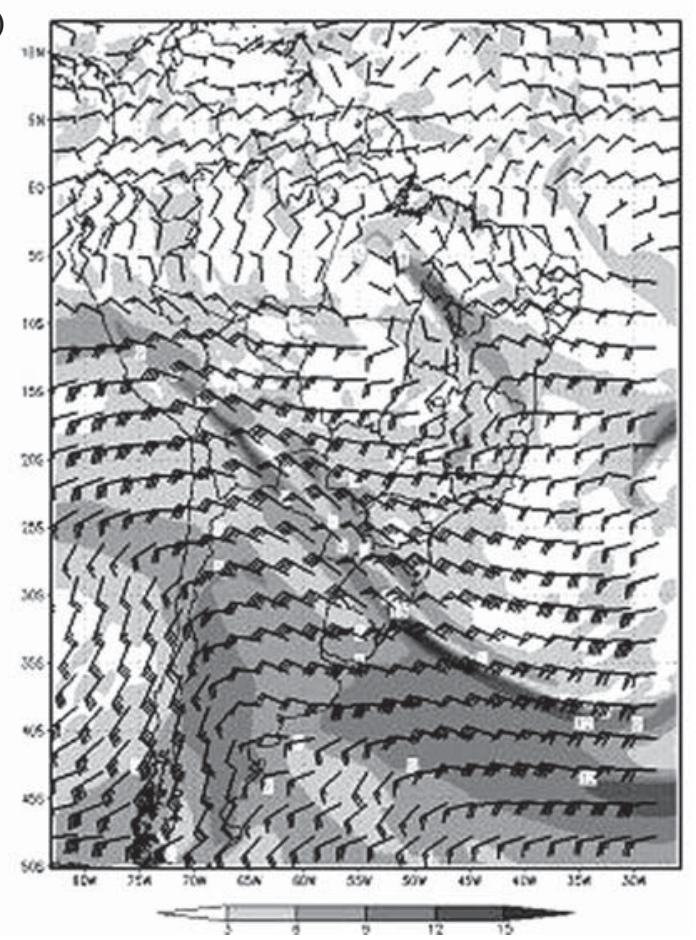

Figura 8 - Indicador de turbulência Brown $\left(10^{-5} \mathrm{~s}^{-1}\right)$ em $250 \mathrm{hPa}$ calculado a partir da saída do modelo ETA para o dia $17 \mathrm{de}$ agosto de 2006 às 0000 UTC com (a) 00h (análise), (b) 24h, (c) 48h e (d) 72h de antecedência. 
a)

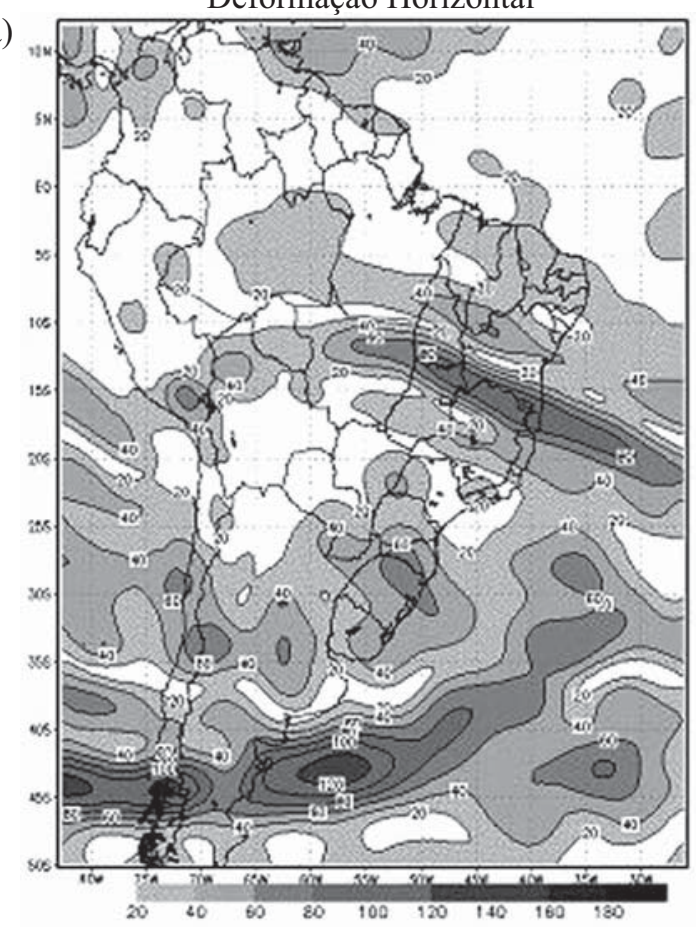

b)

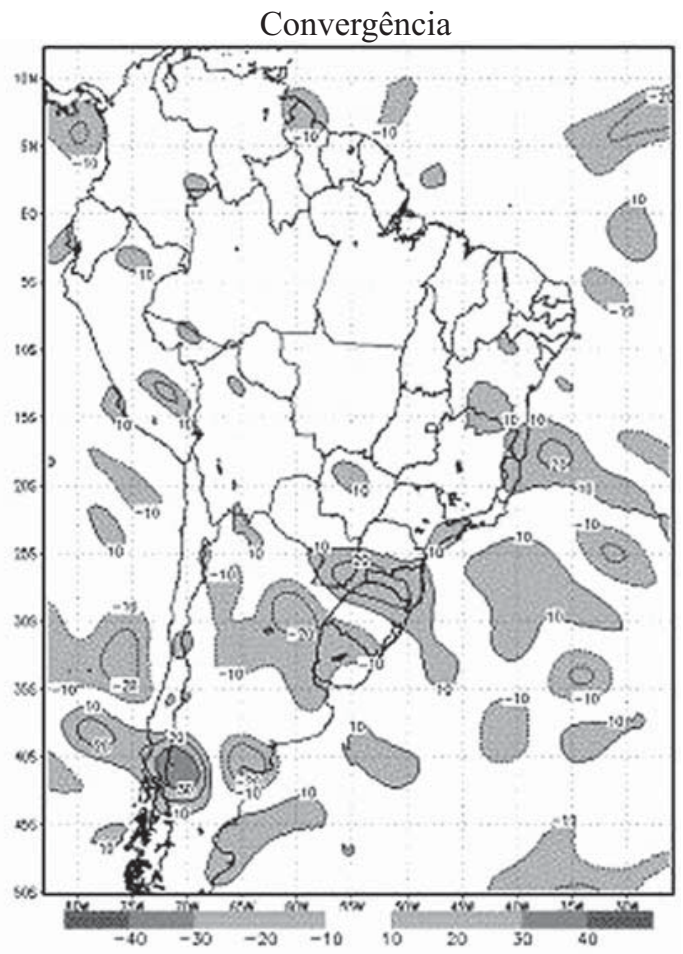

Cisalhamento Vertical

c)

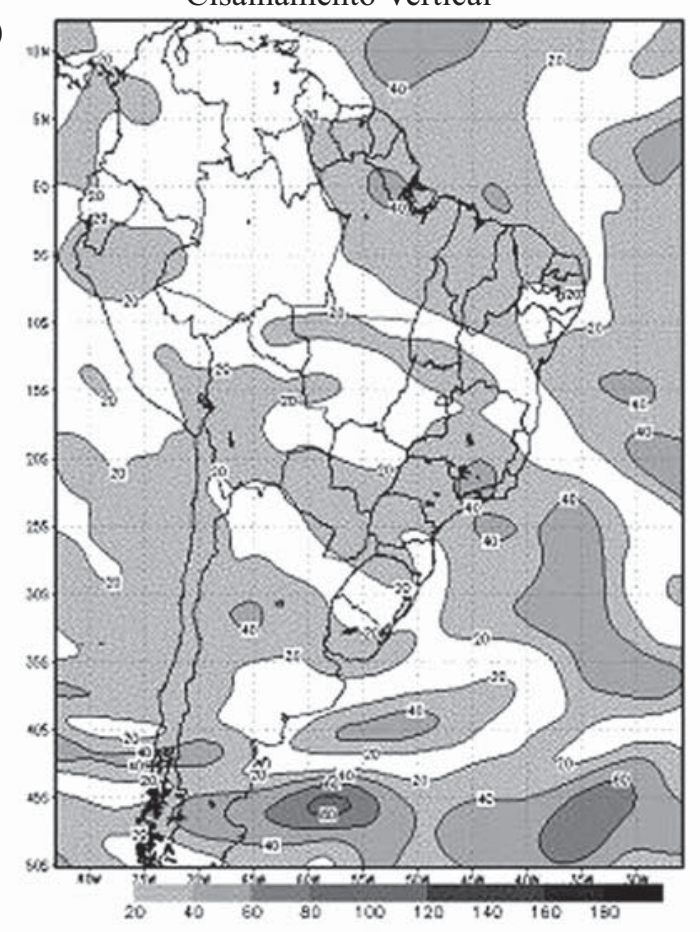

Figura 9 - Análise do NCEP do dia 24 de junho de 2003 às 0000 UTC para os termos (a) de deformação $\left(10^{-6} \mathrm{~s}^{-1}\right)$, (b) convergência $\left(10^{-6} \mathrm{~s}^{-1}\right)$ e (c) cisalhamento vertical $\left(10^{-4} \mathrm{~s}^{-1}\right)$ 
Análise

a)

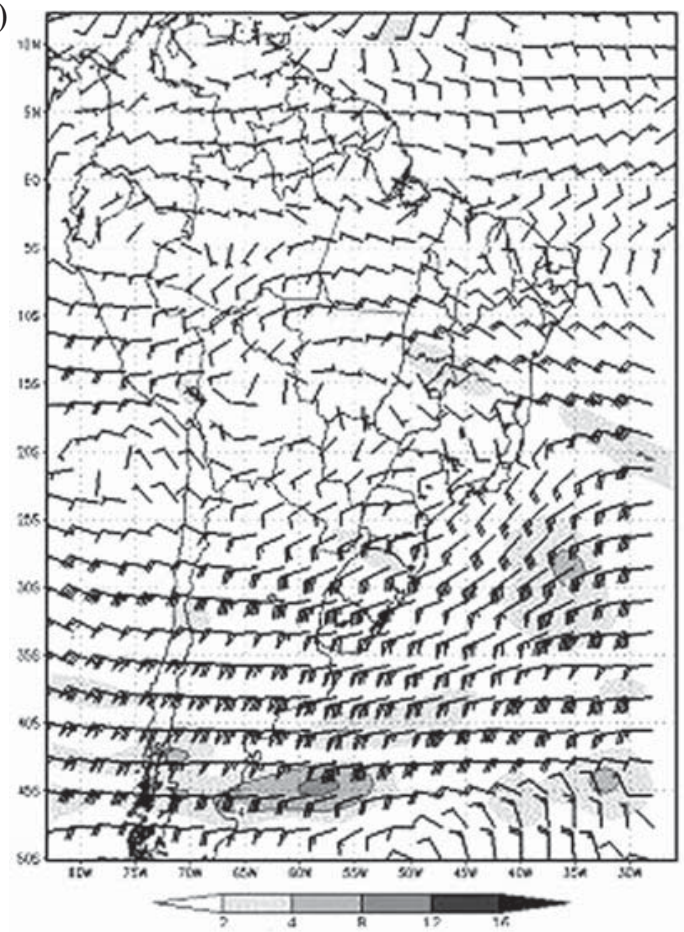

Previsão 48h

c)

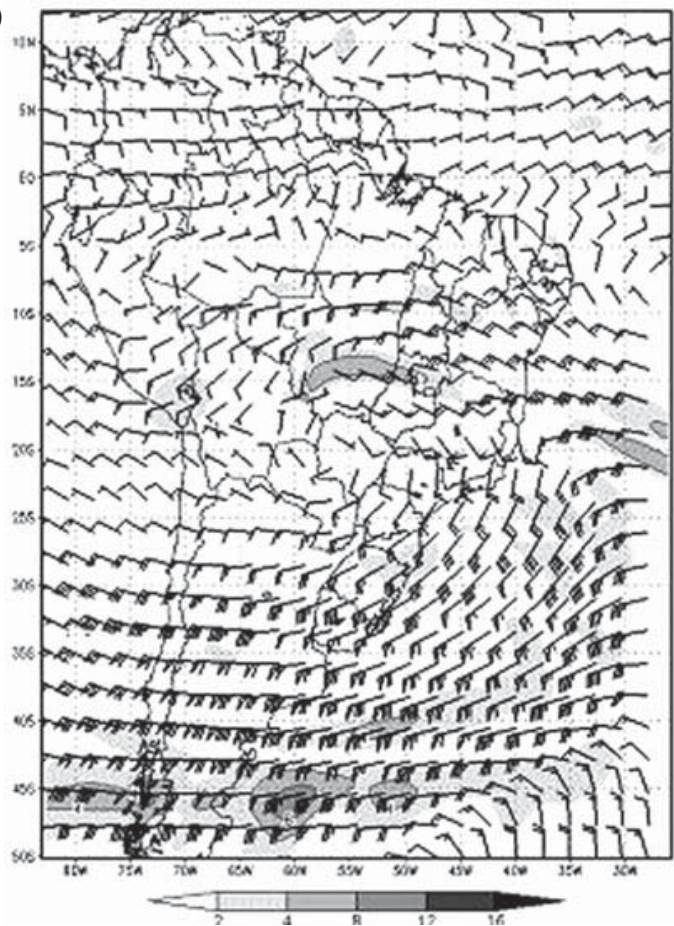

Previsão $24 \mathrm{~h}$

b)

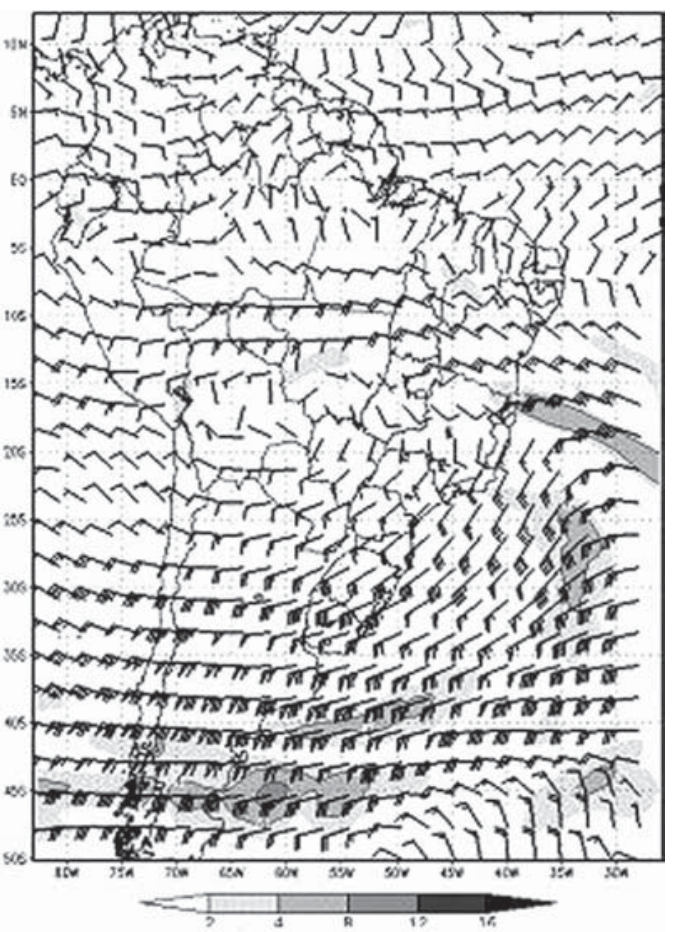

Previsão $72 \mathrm{~h}$

d)

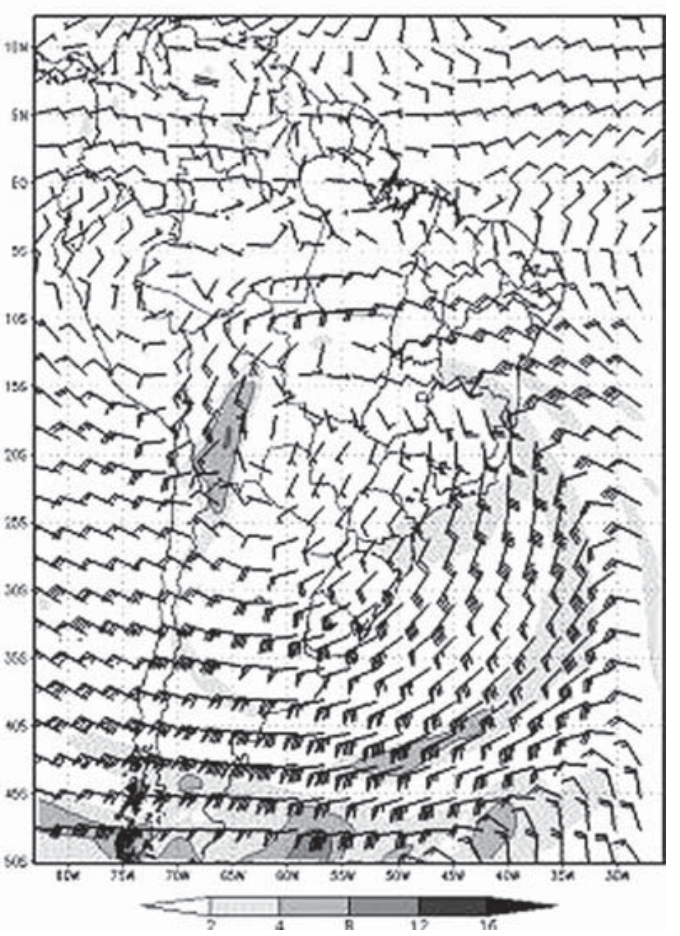

Figura 10 - Indicador de turbulência Ellrod $\left(10^{-6} \mathrm{~s}^{-1}\right)$ entre 300 e $200 \mathrm{hPa}$ calculado a partir da saída do modelo ETA para o dia 24 de junho de 2003 às 0000 UTC com (a) 00h (análise), (b) 24h, (c) 48h e (d) 72h de antecedência. 
Análise

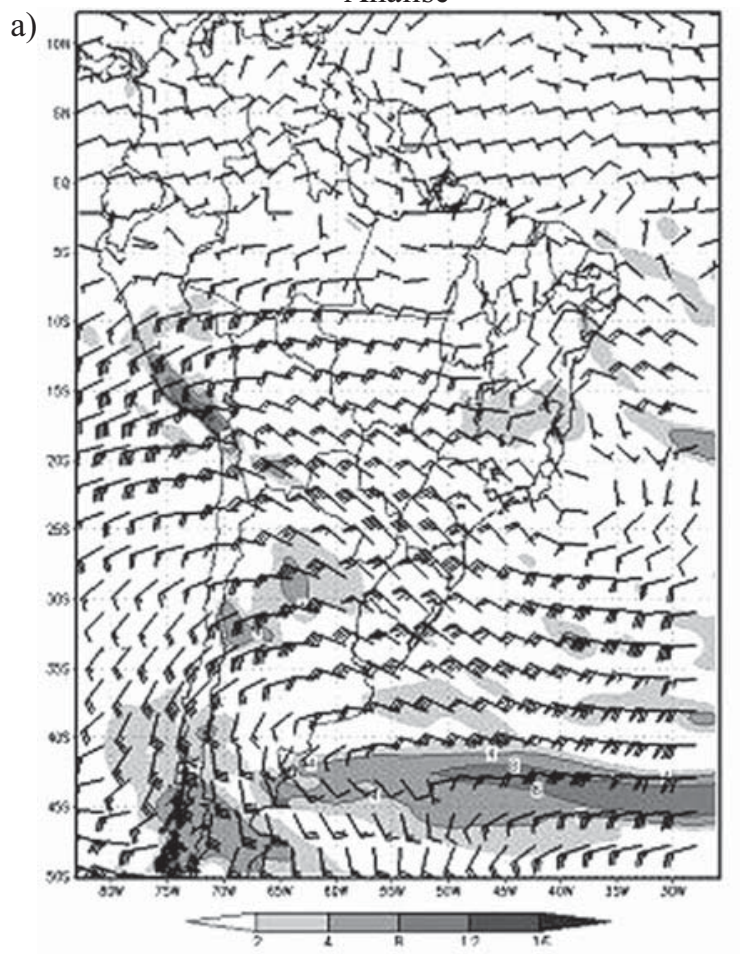

Previsão $48 \mathrm{~h}$

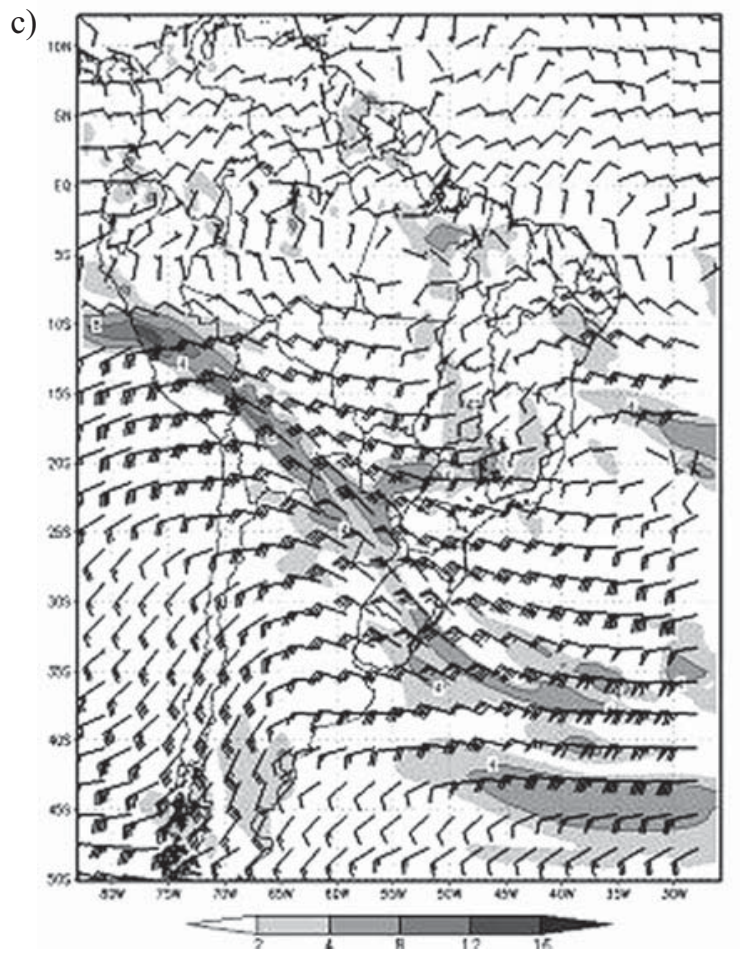

Previsão 24h

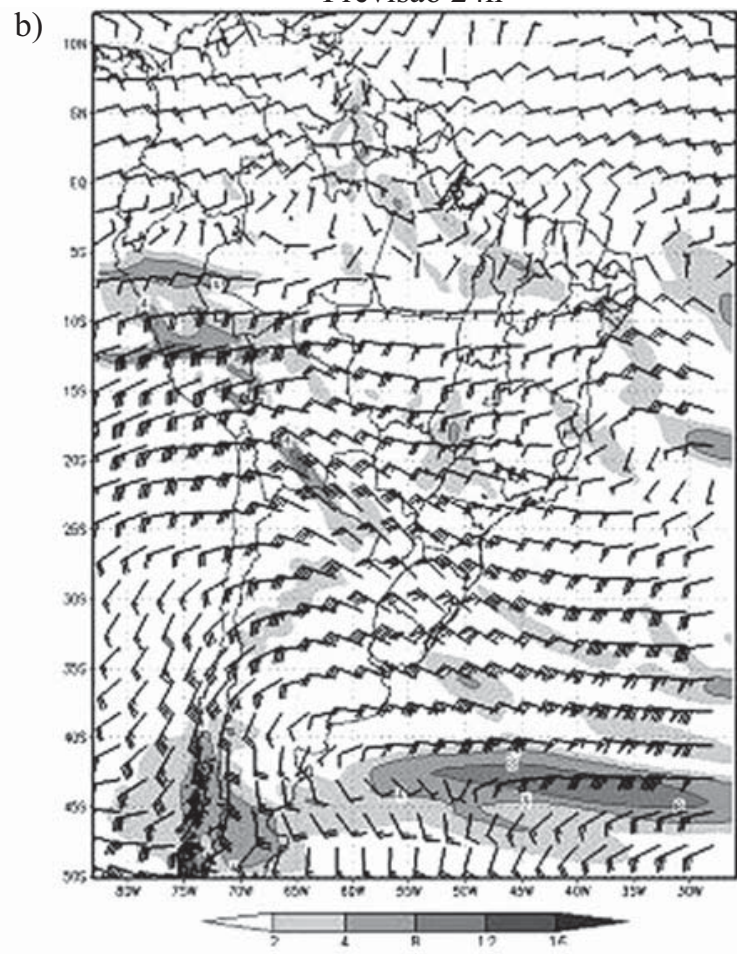

Previsão $72 \mathrm{~h}$

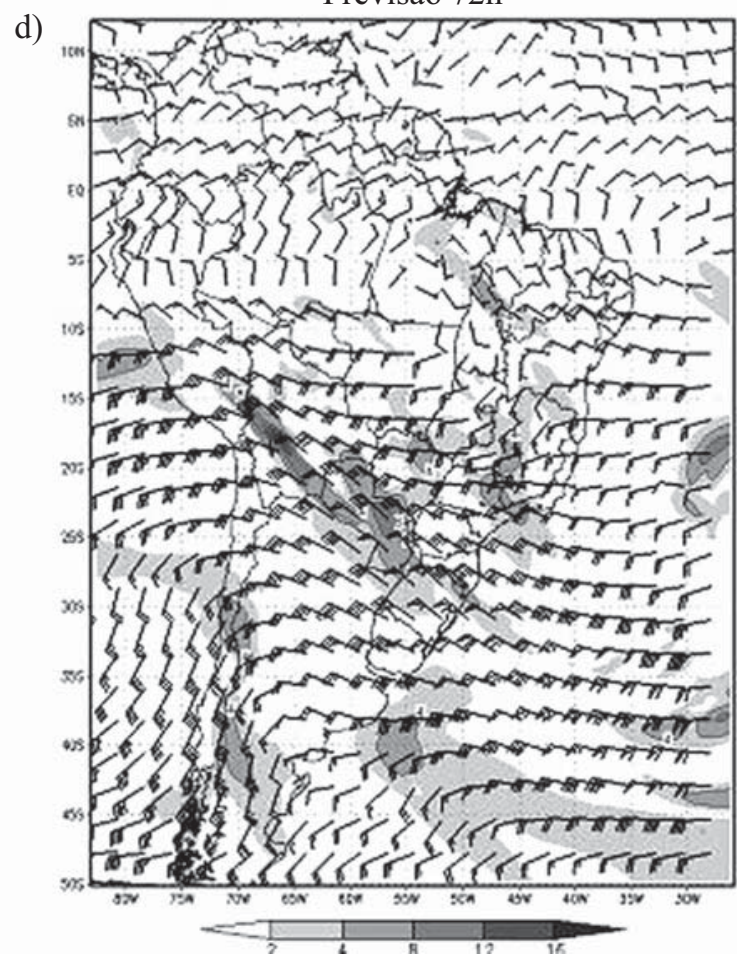

Figura 11 - Indicador de turbulência Ellrod $\left(10^{-6} \mathrm{~s}^{-1}\right)$ entre 300 e $200 \mathrm{hPa}$ calculado a partir da saída do modelo ETA para o dia 17 de agosto de 2006 às 0000 UTC com (a) 00h (análise), (b) 24h, (c) 48h e (d) 72h de antecedência. 

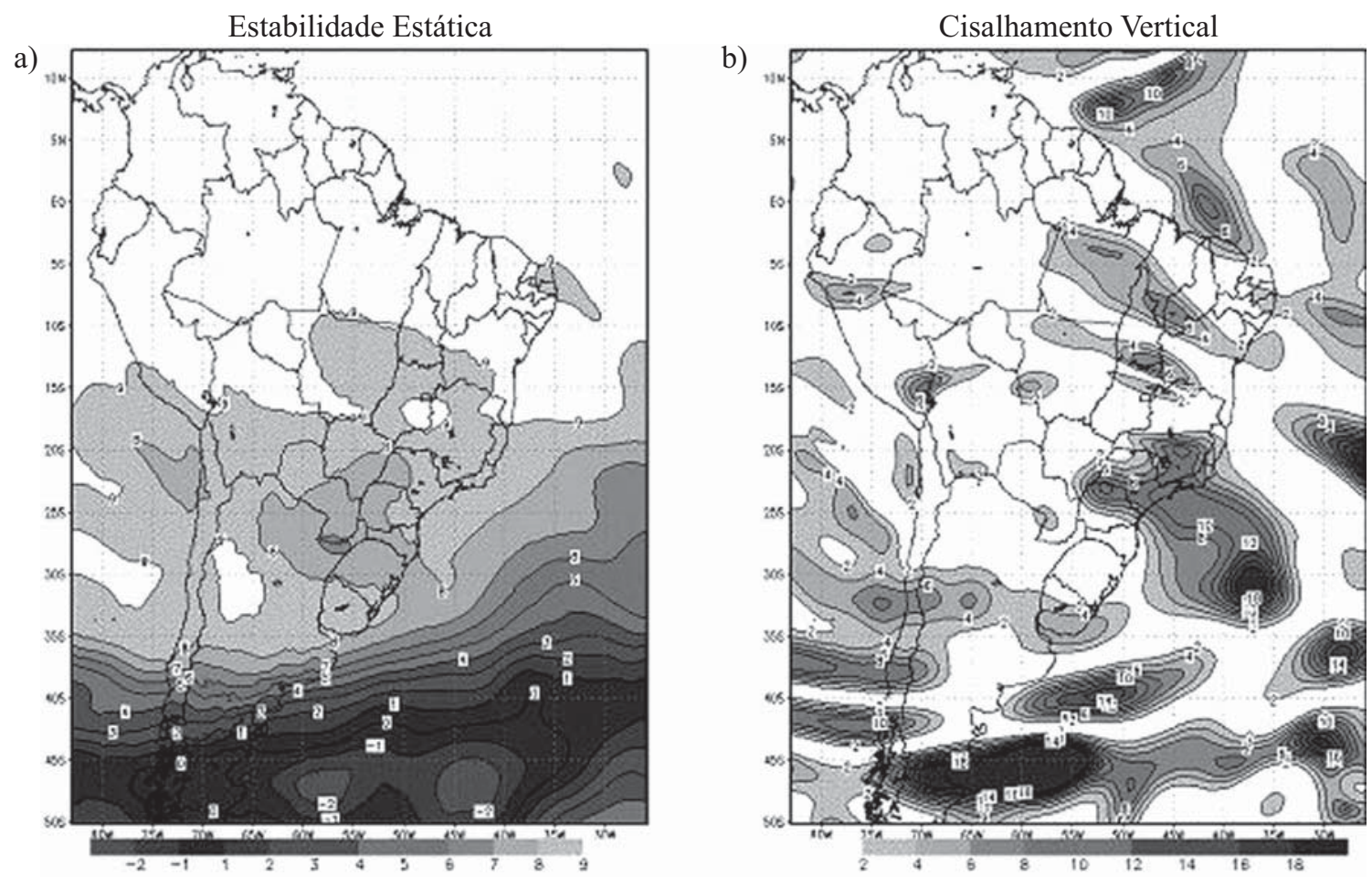

Figura 12 - Análise do NCEP do dia 24 de junho de 2003 às 0000 UTC para os campos de (a) estabilidade estática $\left(10^{-3} \mathrm{~s}^{-1}\right)$ e (b) cisalhamento vertical do vento $\left(10^{-3} \mathrm{~s}^{-1}\right)$.

Para o dia 24 de junho de 2003, as áreas de turbulência foram bem representadas na previsão de 24 horas (Figura 13b). Nas previsões de 48 e 72 horas, o modelo representou áreas de menor extensão tanto para a turbulência associada ao jato quanto para a associada ao sistema frontal (Figuras $13 \mathrm{c}$ e d). Nas previsões para o dia seguinte, o modelo representou as regiões de turbulência com maior extensão e intensidade, e nas previsões de 48 e 72 horas indicaram região de turbulência sobre a Bolívia. No dia 17 de junho de 2006, o modelo previu a região de turbulência abaixo da região de turbulência indicada na carta SIGWX (Figura 14).

\subsubsection{Síntese dos resultados}

Nesta subseção são apresentados os aspectos importantes de cada índice. Tanto no indicador de turbulência Brown como no Ellrod os termos de deformação horizontal, cisalhamento e estiramento foram os que apresentaram maior importância. O indicador Brown tende a intensificar a turbulência próximo as frentes frias. No caso do indicador de turbulência Ri, as regiões de forte cisalhamento vertical foram determinantes para as áreas de turbulência geradas utilizando $\mathrm{o}$ indicador Ri. 
Análise

a)

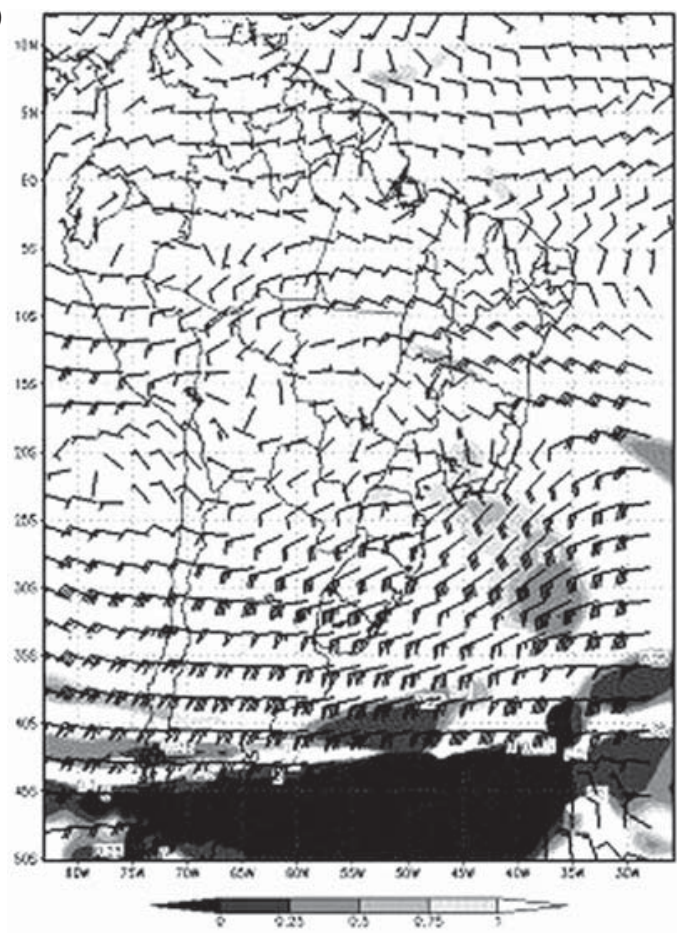

Previsão 48h

c)

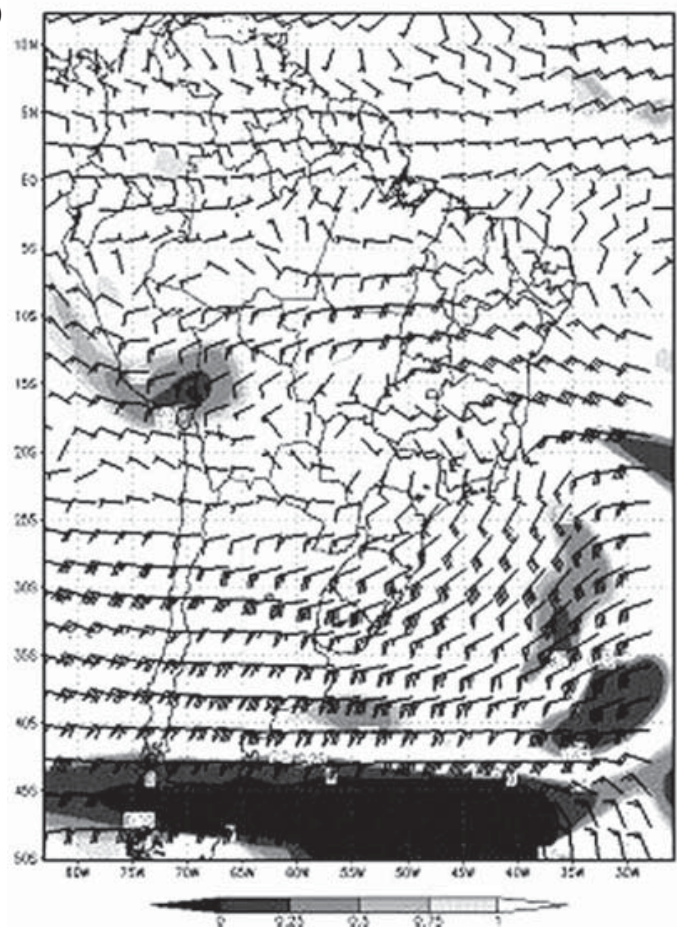

Previsão $24 \mathrm{~h}$

b)

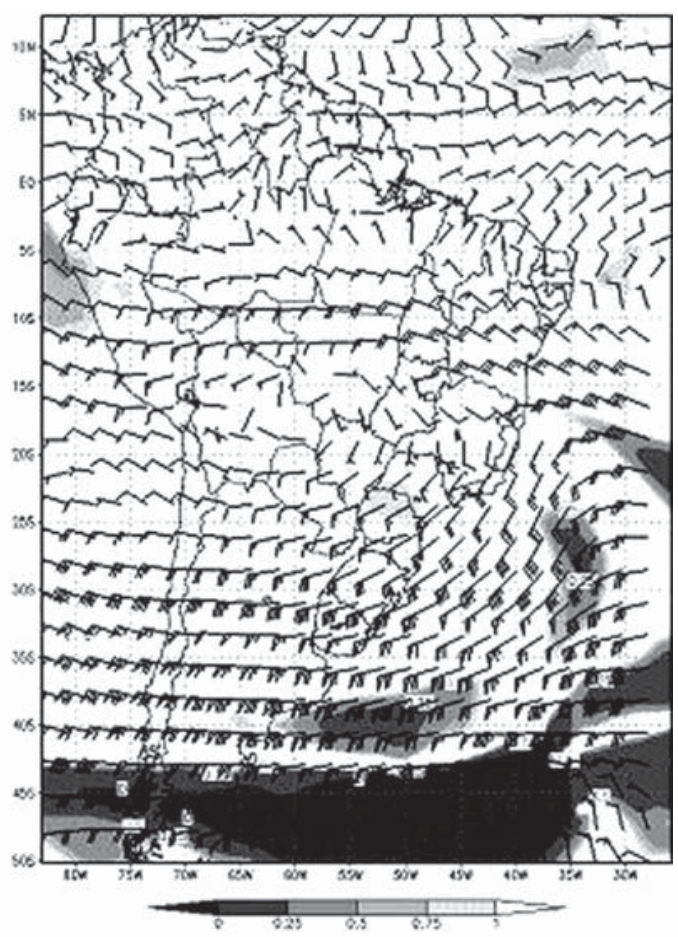

Previsão $72 \mathrm{~h}$

d)

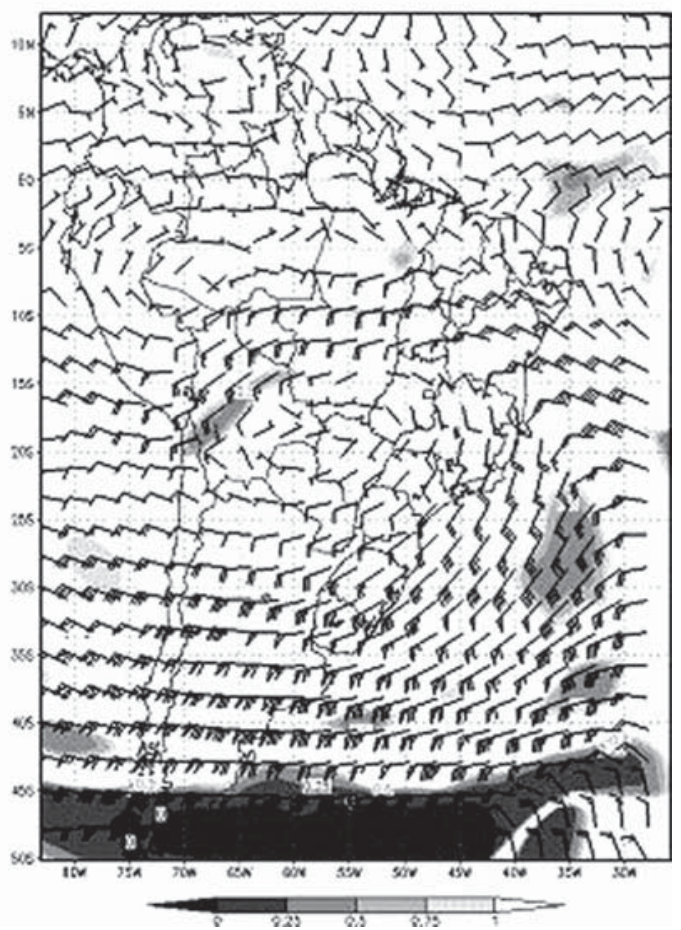

Figura 13 - Indicador de turbulência Ri entre 300 e $200 \mathrm{hPa}$ calculado a partir da saída do modelo ETA para o dia 24 de junho de 2003 às 0000 UTC com (a) 00h (análise), (b) 24h, (c) 48h e (d) 72h de antecedência. 
Análise

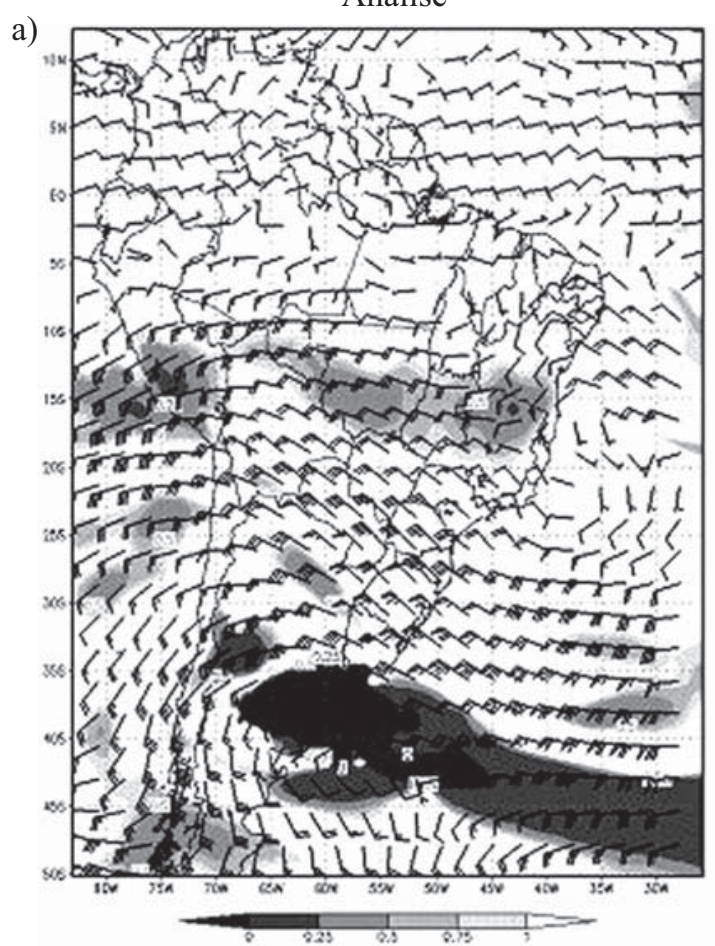

Previsão 48h

c)

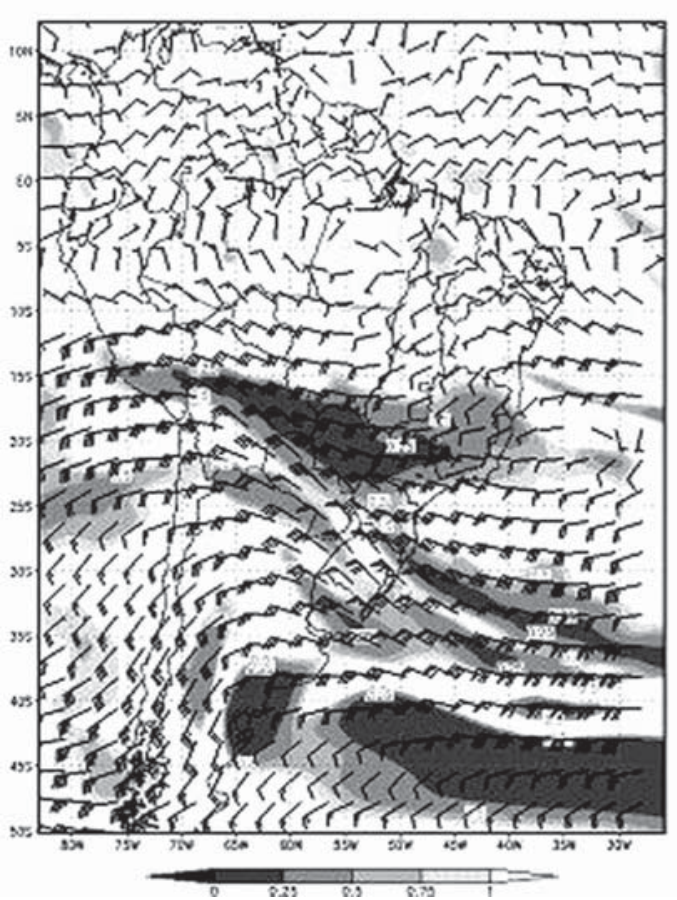

Previsão $24 \mathrm{~h}$

b)

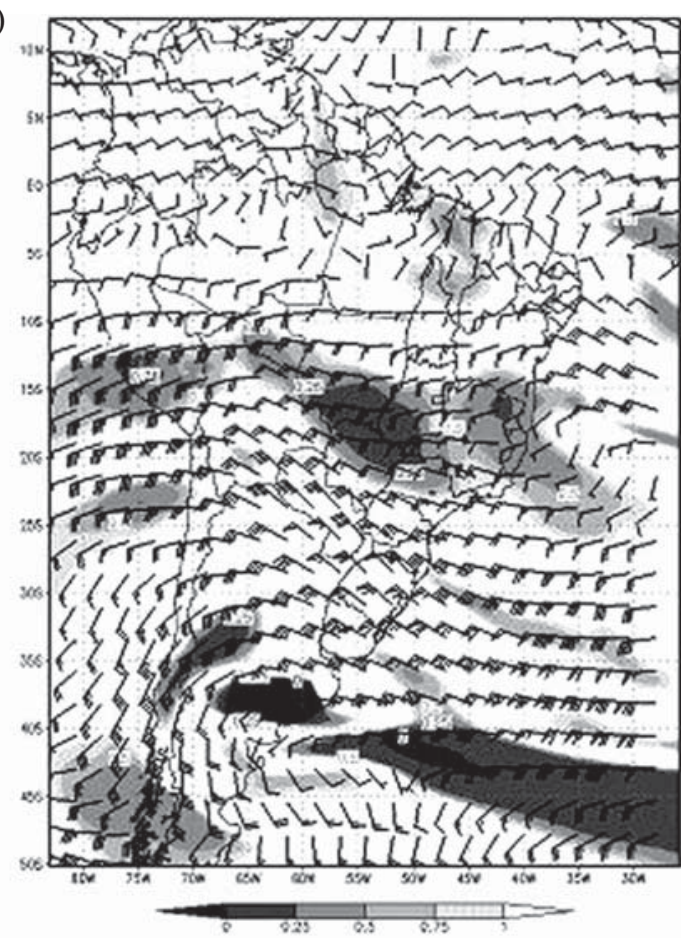

Previsão $72 \mathrm{~h}$

d)

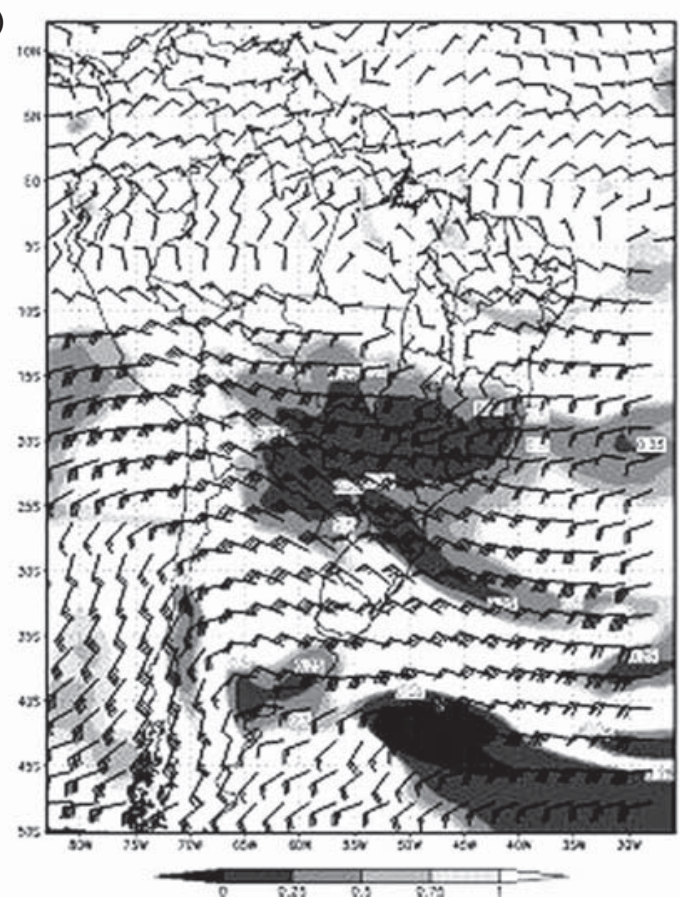

Figura 14 - Indicador de turbulência Ri entre 300 e 200 hPa calculado a partir da saída do modelo ETA para o dia 17 de agosto de 2006 às 0000 UTC com (a) 00h (análise), (b) 24h, (c) 48h e (d) 72h de antecedência. 


\section{CONCLUSÕES}

Neste trabalho foram calculados os indicadores de turbulência $\Phi_{\mathrm{m}}$, ETI e Ri a partir das saídas do modelo regional ETA. Tais indicadores são avaliados para os eventos de 24 de junho de 2003 e 17 de agosto de 2006, confrontando-se os campos gerados objetivamente com as informações contidas nas cartas de tempo significativo SIGWX.

Os termos de cada indicador de turbulência foram analisados separadamente a fim de verificar qual teve maior contribuição para o campo de turbulência. Tanto no indicador de turbulência Brown como no Ellrod os termos de deformação horizontal, cisalhamento e estiramento foram os que apresentaram maior importância. No caso do indicador de turbulência $\mathrm{Ri}$, as regiões de forte cisalhamento vertical foram determinantes para as áreas de turbulência geradas utilizando o indicador Ri.

Os indicadores de turbulência estudados apresentaram boa concordância com as cartas SIGWX. Com até 72 horas de previsão os indicadores conseguiram indicar um sinal da turbulência, enquanto que as cartas SIGWX são previsões subjetivas elaboradas com apenas 24 horas de antecedência. As previsões podem também informar com maior freqüência, por exemplo, a cada 3 horas. A eficiência dos indicadores poderia ser melhor avaliada se os resultados fossem confrontados com informações reportadas por pilotos de aeronaves a respeito de ocorrência de CAT durante o vôo. Contudo, tais informações contidas nas mensagens PIREP, AIREP e AMDAR são pouco freqüentes sobre a América do sul.

Nos eventos estudados foi observado que os indicadores de turbulência Brown e Ellrod representaram melhor a turbulência do que o indicador de turbulência Ri. Entretanto, o período estudado é pequeno para julgar qual dos indicadores realmente detecta melhor a turbulência em ar claro. A combinação do emprego dos três índices é recomendável para aumentar a confiança na previsão. $\mathrm{O}$ aumento do número de estudos de caso deve ser acompanhado pela disponibilização de dados observacionais para validação. Em algumas regiões próximas a corrente de jato, ambos os indicadores apresentaram bons resultados. Isto pode significar maior possibilidade de ocorrência de CAT em tais regiões.

Apesar dos problemas encontrados neste estudo, tais como a falta de dados observacionais para melhor validação dos indicadores de turbulência, pretende-se a partir deste trabalho iniciar o desenvolvimento de um sistema operacional de previsão objetiva de turbulência em ar claro. Tais dados podem auxiliar os pilotos de aeronave no planejamento de rotas de vôo, economia de combustível e nas tomadas de decisão sobre a utilização do uso do cinto de segurança.

\section{REFERÊNCIAS BIBLIOGRÁFICAS}

AXFORD, D. N. On the accuracy of wind measurements using an inertial platform in an aircraft, and an exemple of a measurement of the vertical mesostructure of the atmosphere. J. Appl. Meteor., v.7, 645-666. 1968.

BROWN, R. New indices to locate clear air turbulence. Meteorological Magazine, 102, 347-361. 1973.

COLSON, D. Analysis of clear air turbulence data for march 1962. Mon. Wea. Rev., 91, 73-82, 1963.

CUNDY, R. G. Use of numerical guidance aids in forecasting a turbulence superoutbreak over the eastern United State. Preprints $8^{\text {th }}$ Conf. On aviation, range, and aerospace meteorology, Dallas, TX. Amer. Meteor. Soc., 382-386, 1999.

DUTTON, J. A. Probability of clear-air turbulence based on numerical model output. Meteorologycal Magazine, 109, 293-310, 1980.

DUTTON, J. A.; PANOFSKY, H. A. Clear air turbulence: a mystery may be unfolding. Science, 167, 934-944, 1970.

ELLROD, G. P.; KNAP, D. An objective clear-air turbulence forecasting technique: verification and operational use. Weather and Forecasting, v. 7, 150-165, 1992.

ENDLICH, R. M. The mesoescale structure of some regions of clear air turbulence. J. Appl. Meteor., v.3, 261-276, 1964.

KAPLAN, M. L.; LIN, Y. L.; RIORDAN, A. J.; LUX, K. M.; HUFFMAN, A. W. Observacional and numerical simulation-derived factors that caracterize turbulence accident environments preprints. $9^{\text {th }}$ AMS Conference on Aerospace Range and Aeronautical Meteorology. Sep. 2000, 476-481, 2000..

KELLER J. L. Clear air turbulence as a response to meso- and synoptic-escale dynamic processes. Mon. Wea. Rev., 118, 2228-2242, 1990.

KELLER, T. L.; EHERNBERGER, L. J.; WURTELE, M. G. Numerical Simulation of the atmosphere during a CAT encounter. Preprints, Ninth Conf. On Aerospace and Aeronautical Meteorology, Omaha, Nebraska, Amer. Soc., 316-319, 1983.

KRONEBACH, G. W. An automated procedure for forecasting clear air turbulence. J. Appl. Meteor., v. 3, 2, 119-125, 1964. 
LILLY, D. K. Turbulence in troposphere and stratosphere. FAA Symposium on Turbulence, Washington, D. C, 1971.

MANCUSO, R. L.; ENDLICH, R. M. Clear air turbulence frequency as a function of wind shear and deformation. Mon. Wea. Rev., 95, 581-585, 1966.

NATINOALCOMMITTEE FOR CLEARAIR TURBULENCE, Report to the dept. of commerce, Dec. 1966.

PANTLEY, K. C; LESTER, P. F. Observations of severe turbulence near Thunderstorm tops. J. Appl. Meteor., v.29, 1171-1179, 1990.

REED, R. J.; HARDY, K. R. A case study of persistent, intense clear air turbulence in na upper level frontal zone. J. Appl. Meteor., v. 11, 541-549, 1972.

REITER, E. R. On the nature of clear air turbulence (CAT). Aerospace Engineering, 21, 39-46, 1962.
REITER, E. R.; NANIA, A. Jet-stream structure and clear air turbulence. J. Appl. Meteor., v. 3, 247-260, 1964.

ROACH, W. T. On the influence of synoptic development on the production of high level turbulence. Quart. J. Roy. Meteor. Soc., 96, 413-429, 1970.

ROACH W. T.; BYSOUTH, C. E. How often does severe clear air turbulence occur over tropical oceans, Weather, v. 57, p. 8-19, 2002.

RUSTENBECK, J. D. The association of Richardson's criterion with high level turbulence. Mon. Wea. Rev., 91, 193-168, 1963.

WMO - TECHNICAL NOTE $n^{\circ} 155$, Forecasting Techniques of clear air turbulence including that associated with mountain waves, 1969. 